\title{
Messenger RNA levels of enzymes involved in glycerolipid synthesis in the brain of the mouse and its alterations in Agpat2 $^{/-}$and db/db mice
}

\section{Lila Gonzalez-Hodar}

Pontificia Universidad Catolica de Chile https://orcid.org/0000-0003-2552-7995

\section{Anil K. Agarwal}

University of Texas Southwestern Medical Center at Dallas

Víctor Cortés ( $\nabla$ vcortesm@uc.cl)

University of Texas Southwestern Medical Center at Dallas https://orcid.org/0000-0002-1658-0965

\section{Research}

Keywords: glycerolipid, brain, Agpat2, leptin receptor, insulin resistance, type 2 diabetes

Posted Date: December 16th, 2020

DOl: https://doi.org/10.21203/rs.3.rs-128675/v1

License: (c) (1) This work is licensed under a Creative Commons Attribution 4.0 International License.

Read Full License 


\section{Abstract \\ Background and Aims:}

Expression of genes encoding enzymes involved in glycerolipid and monoacylglycerol pathways in specific brain regions is poorly known and their alterations in insulin resistance (IR) and type 2 diabetes (T2D) remain unreported. We determined the mRNA levels of enzymes involved in glycerolipid synthesis in specific regions of the mouse brain and their changes in two models of severe IR, the lipodystrophic Agpat $^{-/-}$and the obese $L e p r^{\mathrm{db} / \mathrm{db}}$ mice.

\section{Methods}

Cerebral cortex, hypothalamus, hippocampus and cerebellum were dissected from adult Agpat2 $^{-/-}$mice, $L e p r^{\mathrm{db} / \mathrm{db}}$ mice and their respective wild type littermates. Total RNA was isolated and the relative mRNA abundance of enzymes was determined by RT-qPCR.

\section{Results}

GPAT1, AGPAT1-4, LIPIN1/2, DGAT1/2 and MOGAT1 mRNAs were detected in all studied brain regions, whereas GPAT2, LIPIN3 and MOGAT2 were undetectable. Abundance of GPAT1, AGPAT1, AGPAT2, AGPAT4, LIPIN1, and MOGAT1, was higher in the hypothalamus. AGPAT3 and DGAT1 were higher in cortex and cerebellum, and LIPIN2 and DGAT2 were higher in cortex and hippocampus. In Agpat2 ${ }^{-1-}$ mice, LIPIN1 levels were increased in all the brain regions. By contrast, GPAT1 and AGPAT4 in hypothalamus, AGPAT3 in hippocampus and hypothalamus, and MOGAT1 in cortex, hypothalamus and cerebellum were lower in Agpat2 ${ }^{-/-}$mice. Lepr ${ }^{\mathrm{db} / \mathrm{db}}$ mice showed fewer and milder changes, with increased levels of GPAT1 and LIPIN1 in cerebellum, and AGPAT3 in hypothalamus.

\section{Conclusions}

Enzymes involved in glycerolipids synthesis are differentially expressed across regions of the mouse brain and IR and T2D determine altered gene expression of these enzymes in the mouse brain.

\section{Background}

Type 2 diabetes (T2D) is associated with abnormalities in the structure and functioning of the brain (1). These changes include reduced brain and hippocampus volume and impaired attention, executive function, information processing, visuospatial construction and visual memory (1). In mice, high-fat dietinduced insulin resistance (IR) and hyperglycemia result in loss of neurons and reduced olfactory learning (2). 
Glycerophospholipids and diacylglycerol regulate signaling, apoptosis, membrane anchoring, and antioxidant capacity in the brain (3). Incubation of rat brain tissue sections with the phosphatidylserine (PS) increases a-amino-3-hydroxy-5-methyl-4-isoxazolepropionic acid (AMPA) binding to AMPA glutamate receptors without modifying glutamate binding to $N$-methyl-D-aspartate (NMDA) receptor, indicating that PS specifically regulates AMPA receptor binding activity (4). Because blood brain barrier limits lipid trafficking, de novolipogenesis is the main source of glycerolipids in the brain (5).

Glycerolipids are synthesized by sequential acylation of glycerol-3-phosphate or monoacylglycerol. The first intermediate in glycerol-3-phosphate pathway is lysophosphatidic acid (LPA; 1-acylglycerol 3phosphate) which is formed by glycerol-3-phosphate acyltransferases (GPATs). LPA is then acylated in sn2 position by 1-acylglycerol-3-phosphate acyltransferases (AGPATs), forming phosphatidic acid (PA; 1,2 diacylglycerol phosphate). Phosphate group of PA is removed by phosphatidic acid phosphatases (PAPs, LIPINs), resulting in diacylglycerol (DAG) which is then acylated in sn3 position by diacylglycerol acyltransferases (DGATs) to generate triacylglycerol (TAG) (6). DGATs activity has been reported in very low levels in the brain (7). Monoacylglycerol pathway starts with acylation of 2-monoacylglycerol by monoacylglycerol acyltransferases (MOGATs) to form DAG, which is further acylated by DGATs to produce TAG (7).

All enzymes involved in glycerolipid synthesis have multiple isoforms encoded by individual genes with differential tissue expression patterns (8). Although some of these enzymes have been reported, at the mRNA level, in whole brain homogenates $(6,8)$, their expression across specific regions of the brain remains unknown. Furthermore, the effects of IR and T2D on the abundance of these enzymes in the brain have not been reported.

Agpat2 null $\left(\right.$ Agpat $\left.^{\prime-}\right)$ mice lack white and brown adipose tissue and develop severe IR, diabetes, dyslipidemia and fatty liver (9) as a result of leptin deficiency (10). Mice with inactivating mutations in leptin receptor ( $L e p r^{\mathrm{db} / \mathrm{db}}$ ) also develop IR and T2D, but, opposite to Agpat2/- mice, develop severe obesity as a result of hyperphagia and decreased energy expenditure $(11,12)$. Progressive hyperglycemia and hyperinsulinemia start at the sixth week of age in $L e p r^{\mathrm{db} / \mathrm{db}}$ mice and severe hyperglycemia is already present at the fourteenth week.

In this study we aimed to quantify the mRNA levels of enzymes involved in the glycerolipid synthesis pathway across different regions of the mouse brain and to determine the differences in the expression level between two models of severe IR and diabetes. In spite of the similar metabolic abnormalities between Agpat2 $^{-/-}$and $L e p r^{\mathrm{db} / \mathrm{db}}$ mice we found that whereas $L e p r^{\mathrm{db} / \mathrm{db}}$ had few and small changes compared to wild type mice, Agpat2 ${ }^{-/-}$mice had several changes that might be owed to specific lipid composition perturbation derived from AGPAT2 deficiency rather than to primary metabolic alterations.

\section{Methods}


Animals: Mice were housed 3-4 per cage, maintained on a $12 \mathrm{~h}$ light/12 $\mathrm{h}$ dark cycle and fed a standard chow diet (Prolab RMH 3000; LabDiet, St. Louis, MO) ad libitum. Generation of Agpat2 ${ }^{-1-}$ mice has been described previously (9). Agpat2 ${ }^{-/-}$and Agpat2 $^{+/+}$mice were obtained by mating of Agpat2 $^{+/-}$mice. $L e p r^{+/+}$and $L e p r^{d b / d b}$ mice were generated by mating of $L e p r^{+/ d b}$ mice (obtained from The Jackson Laboratory, Bar Harbor, ME). Agpat2 ${ }^{/-}$, Agpat2 $^{+/+}$, Lepr ${ }^{d b / d b}$ and Lepr ${ }^{+/+}$adult mice (9-14 weeks) of both sexes were anesthetized by ketamine/xylazine $(100: 10 \mathrm{mg} / \mathrm{Kg})$ and euthanized by exsanguination under deep anesthesia. The brain was extracted and dissected into cerebral prefrontal cortex, hypothalamus, hippocampus and cerebellum and flash frozen in liquid nitrogen and stored at $-80^{\circ} \mathrm{C}$. For the brain dissection, we placed the whole brain in a petri dish on ice. First, we put the brain's ventral side up, and we extracted the hypothalamus with curved tweezers. Then, we placed the dorsal side of the brain up, and we dissected the cerebellum, separating it from the medulla and the pons. We cut the cerebellum with a surgical blade into the right and left cerebellum. After, we made a sagittal cut of the brain, dividing the brain into two hemispheres, left and right. For each hemisphere, we freed the hippocampus, separating it from the cortex using a curved serrated forceps. Once the hippocampus was freed, it was dissected with the same forceps. Finally, the prefrontal cortex was picked up with the forceps. All mouse procedures were reviewed and approved by the Institutional Animal Care and Use Committee (IACUC) at Pontificia Universidad Católica de Chile (ID 170717017).

\section{RNA extraction and cDNA preparation}

The hypothalamus, left prefrontal cortex, left hippocampus and left cerebellum were homogenized with Mixer mill (Retsch Inc, Newtown, CT) and total RNA extracted using Trizol ${ }^{\circledR}$ reagent (Invitrogen, Carlsbad, $\mathrm{CA}$ ) following manufacturer's instructions. RNA was resuspended with RNAsecure solution (Invitrogen, Carlsbad, CA). RNA concentration was determined by Nanodrop spectrophotometer Nanodrop 2000 (Thermo Fisher Scientific, Waltham, MA). To evaluate the RNA integrity, $1 \mu \mathrm{g}$ of RNA was visualized in denaturing agarose/formaldehyde gels. Residual genomic DNA was eliminated with Turbo DNA-free kit (Invitrogen, Carlsbad, CA). $2 \mu \mathrm{g}$ of total RNA were reverse transcribed with High Capacity cDNA Reverse Transcription Kit (Applied Biosystems, Foster City, CA) following manufacturer's instructions.

\section{mRNA quantification by reverse transcription real time PCR (RT-qPCR)}

Real-time qPCR reactions were performed in Applied Biosystems StepOnePlus thermalcycler using Fast SYBR ${ }^{\circledR}$ Green Master Mix (Applied Biosystems, Foster City, CA) with 25 ng of template cDNA. Thermal cycling involved an initial step at $95^{\circ} \mathrm{C}$ for 20 seconds and then 40 cycles at $95^{\circ} \mathrm{C}$ for 3 seconds and $60{ }^{\circ} \mathrm{C}$ for 30 seconds. PCR primer sequences are presented in Table 1. To determine the relative abundance of specific mRNAs across different brain regions, target gene cycle threshold (Ct) value (cut off $=30)$ was normalized to the $\mathrm{Ct}$ value of the reference gene cyclophilin (Ppib) using $2^{-\Delta C t}$ method $\left(2^{-}\right.$ (CT target gene - CT reference gene)). The relative mRNAs abundance of target genes in specific brains regions of wild type and Agpat2 $^{-/-}$or $L e p r^{d b / d b}$ mice was determined by the $2^{-\triangle \Delta C T}$ method with Ppib as reference gene. The organization of all PCR plates used in this work are shown in supplementary table S6. 
Table 1

Sequence of PCR primers used for quantification of mRNAs by real time qPCR.

\begin{tabular}{|c|c|c|c|}
\hline Gene name & Abbreviated & \multicolumn{2}{|c|}{ Sequence $\left(5^{\prime} \rightarrow 3^{\prime}\right)$} \\
\hline \multirow{2}{*}{$\begin{array}{l}\text { Glycerol-3-phosphate } \\
\text { acyltransferase } 1\end{array}$} & \multirow[t]{2}{*}{ GPAT1 } & Forward & CAACACCATCCCCGACATC \\
\hline & & Reverse & GTGACCTTCGATTATGCGATCA \\
\hline \multirow{2}{*}{$\begin{array}{l}\text { Glycerol-3-phosphate } \\
\text { acyltransferase } 2\end{array}$} & \multirow[t]{2}{*}{ GPAT2 } & Forward & ACCAGCCTTTGGTCCTCAAG \\
\hline & & Reverse & AAGAGGGACTCCCAGCTCTT \\
\hline \multirow{2}{*}{$\begin{array}{l}\text { 1-acylglycerol-3-phosphate } \\
\text { acyltransferase } 1\end{array}$} & \multirow[t]{2}{*}{ AGPAT1 } & Forward & GCTGGCTGGCAGGAATCAT \\
\hline & & Reverse & GTCTGAGCCACCTCGGACAT \\
\hline \multirow{2}{*}{$\begin{array}{l}\text { 1-acylglycerol-3-phosphate } \\
\text { acyltransferase } 2\end{array}$} & \multirow[t]{2}{*}{ AGPAT2 } & Forward & TTTGAGGTCAGCGGACAGAA \\
\hline & & Reverse & AGGATGCTCTGGTGATTAGAGATGA \\
\hline \multirow{2}{*}{$\begin{array}{l}\text { 1-acylglycerol-3-phosphate } \\
\text { acyltransferase } 3\end{array}$} & \multirow[t]{2}{*}{ AGPAT3 } & Forward & CCAGTGGCTTCACAAGCTGTAC \\
\hline & & Reverse & ССCTGGGAATACACCCTTCTG \\
\hline \multirow{2}{*}{$\begin{array}{l}\text { 1-acylglycerol-3-phosphate } \\
\text { acyltransferase } 4\end{array}$} & \multirow[t]{2}{*}{ AGPAT4 } & Forward & ACTTCGTGGAAATGATCTTTTGC \\
\hline & & Reverse & GAGGTGCAGCAGGCTCTTG \\
\hline \multirow[t]{2}{*}{ Lipin1 } & \multirow[t]{2}{*}{ LIPIN1 } & Forward & GAGCATGCCAAGACCAACATC \\
\hline & & Reverse & CAATGGGAAGACGTGATCGA \\
\hline \multirow[t]{2}{*}{ Lipin2 } & \multirow[t]{2}{*}{ LIPIN2 } & Forward & GCATTAACCAAGCCACGTTGT \\
\hline & & Reverse & AAAGGCGAGCACTGGTAGGA \\
\hline \multirow[t]{2}{*}{ Lipin3 } & \multirow[t]{2}{*}{ LIPIN3 } & Forward & GACTGCCTAAGGTGGCGAAAG \\
\hline & & Reverse & CACAGATCGCCTCAGCCATA \\
\hline \multirow[t]{2}{*}{ Diacylglycerol acyltransferase 1} & \multirow[t]{2}{*}{ DGAT1 } & Forward & GAGGCCTCTCTGCCCCTATG \\
\hline & & Reverse & GCCCCTGGACAACACAGACT \\
\hline \multirow[t]{2}{*}{ Diacylglycerol acyltransferase 2} & \multirow[t]{2}{*}{ DGAT2 } & Forward & CCGCAAAGGCTTTGTGAAG \\
\hline & & Reverse & GGAATAAGTGGGAACCAGATCA \\
\hline \multirow{2}{*}{$\begin{array}{l}\text { Monoacylglycerol } \\
\text { acyltransferase } 1\end{array}$} & \multirow[t]{2}{*}{ MOGAT1 } & Forward & GAGTAACGGGCCGGTTTCA \\
\hline & & Reverse & AGACATTGCCACCTCCATCCT \\
\hline \multirow{2}{*}{$\begin{array}{l}\text { Monoacylglycerol } \\
\text { acyltransferase } 2\end{array}$} & \multirow[t]{2}{*}{ MOGAT2 } & Forward & GCCCATCGAGGTGCAGAT \\
\hline & & Reverse & AGAGCTCCTTGATATAGCGCTGAT \\
\hline
\end{tabular}




\section{Statistical analysis}

Given the small size of the samples in this work, no normality tests were used $(14,15)$. Data was logtransformed, as biological variables often follow lognormal distribution $(16,17)$, and means were compared with parametrical tests (18-21).

For two-group comparison, mean values were compared with two-sided Student's t-test. For experiments with more than two groups, mean values were analyzed by one-way ANOVA and Bonferroni post-hoc test for multiple comparisons. GraphPad Prism version 6.00 (GraphPad, La Jolla, CA) was used for plotting, logarithmic transformation, and statistical analyses. Figure 4 was created with BioRender.com. All the raw cycle threshold data as well as the configuration of all qPCR procedures is detailed in the supplemental material.

\section{Results}

\section{Quantification of the mRNA levels of enzymes involved in glycerolipid synthesis in different regions of the mouse brain.}

A systematic gene expression analysis of the enzymes involved in glycerolipid synthesis in different regions of the brain is lacking. We quantified the mRNA abundance of the main isoforms of these enzymes in the mouse cerebral cortex, hypothalamus, hippocampus and cerebellum.

GPATs mediate the first reaction in the glycerol-3-phosphate pathway, generating LPA. GPAT1 mRNA was detected in all the regions studied and its highest abundance was found in the hypothalamus, followed by the cerebellum and cortex, and then the hippocampus (Fig. 1A). GPAT2 mRNA was undetectable in all the brain regions.

AGPATs generate PA from LPA. Among the four AGPAT isoforms that we quantified (AGPAT1-4), the most abundant was AGPAT4 whereas AGPAT2 had the lowest expression levels (Fig. 1B). Interestingly, the hypothalamus had the highest expression level of AGPAT4 and AGPAT2. The highest abundance of AGPAT1 was in the cortex and hypothalamus, while AGPAT3 has its highest expression level in the cortex and cerebellum. The lowest abundance of AGPAT3 and AGPAT4 was in hippocampus; whereas the lowest levels of AGPAT1 and AGPAT2 was in the cerebellum and cortex, respectively (Fig. 1B).

LIPINs are phosphatidic acid phosphatases enzymes that transform PA into DAG. The mRNA of LIPIN1 and LIPIN2 was detected in all the brain structures analyzed (Fig. 1C); however, LIPIN1 mRNA abundance was significantly higher in the hypothalamus and cerebellum in comparison with cerebral cortex and hippocampus. By contrast, the highest expression level of LIPIN2 was in the cortex, followed by the hippocampus, hypothalamus, and, finally, cerebellum. Interestingly, LIPIN2 was the predominant isoform 
in the cortex and hippocampus whereas in the cerebellum and hypothalamus the most abundant isoform was LIPIN1 (Fig. 1C). LIPIN 3 mRNA was undetectable in all the studied structures.

DGAT1 and DGAT2 mRNAs were detected in all the brain regions studied, although at low levels. Of these, DGAT2 was the most abundant although its highest levels were in the cortex and hippocampus, followed by the hypothalamus, and finally the cerebellum (Fig. 1D). The highest abundance of DGAT1 mRNA was in the cortex and cerebellum, followed by the hypothalamus and hippocampus.

MOGATs produce DAG from monoacylglycerol. MOGAT1 mRNA was detected in all the studied regions of the brain, but at very low levels, with its highest abundance in the hypothalamus. MOGAT2 mRNA was undetectable (Fig. 1E).

\section{Effects of AGPAT2 and leptin receptor deficiency on the mRNA levels of glycerolipid biosynthetic enzymes in the mouse brain.}

To assess the effect of IR and T2D on the mRNA levels of glycerolipid biosynthetic enzymes, we studied two independent mouse models of leptin action deficiency, the lipodystrophic Agpat2 ${ }^{-/-}$and the obese $L e p r^{\mathrm{db} / \mathrm{db}}$ mice. Overall, only small differences were detected between these mouse models and wild type mice (Figs. 2 and 3).

In Agpat2 $^{-/-}$mice, GPAT1 mRNA levels were slightly lower in the hypothalamus ( $p$ value $=0.0214$ ) compared to wild type $\left(\right.$ Agpat $\left.^{+/+}\right)$mice but remained equivalent in all the other brain regions (Fig. $\left.2 A\right)$.

No differences in AGPAT1 mRNA levels were detected in any of the studied brain regions but the abundance of AGPAT3 mRNA was slightly lower in the hypothalamus ( $p$ value $=0.0481$ ) and hippocampus ( $p$ value $=0.0085)$ and AGPAT4 mRNA was only lower in the hypothalamus $(p$ value $=$ 0.0341) in Agpat2 $^{-/-}$mice. As expected, AGPAT2 mRNA was undetected in the brain of Agpat2 $^{-/-}$mice (Fig. 2B).

LIPIN1 mRNA showed the highest differential abundance in Agpat2 ${ }^{-1-}$ mice, with $\sim 2$-fold increase in the cerebral cortex ( $p$ value $=0.0182)$ and hypothalamus ( $p$ value $=0.0263$ ) and $\sim 1.5$-fold increase in the cerebellum ( $p$ value $=0.0183$ ) and hippocampus $(p$ value $=0.0329)$. No differences were detected in the abundance of LIPIN2 mRNA between genotypes (Fig. 2C). Interestingly, LIPINs have reported roles in brain function. LIPIN2 deficient mice develop ataxia and decreased LIPIN1 levels, resulting in altered cerebellar phospholipid composition (22). In humans, the splicing isoform LIPIN1y is highly expressed in the brain (23), suggesting a regulatory role on brain glycerolipid metabolism.

DGAT1 and DGAT2 mRNA levels were equivalent between Agpat2 $^{-/-}$and wild type mice (Fig. 2D). By contrast, MOGAT1 was strongly decreased in the cerebral cortex ( $p$ value $=0.0269)$, hypothalamus $(p$ value $=0.0248)$ and cerebellum ( $p$ value $=0.0225)$ of Agpat $^{-/-}$mice but unchanged in the hippocampus (Fig. 2E). 
$L e p r^{\mathrm{db} / \mathrm{db}}$ mice showed fewer and smaller differences compared to wild type mice than Agpat2 ${ }^{-/-}$mice (Fig. 3). The abundance of GPAT1 mRNA in the cerebellum in these animals was higher compared to wild type $\left(\mathrm{Lepr}^{+/+}\right)$mice ( $\mathrm{p}$ value $\left.=0.0196\right)(\mathrm{Fig} .3 \mathrm{~A})$, with no further differences detected in the other regions of the brain.

Among AGPAT isoforms, only AGPAT3 mRNA levels were slightly increased in the hypothalamus of $L e p r^{\mathrm{db} / \mathrm{db}}$ mice $(\mathrm{p}$ value $=0.0406)($ Fig. $3 \mathrm{~B})$.

Similarly, LIPIN1 was increased only in the cerebellum of $L e p r^{\mathrm{db} / \mathrm{db}}$ mice ( $\mathrm{p}$ value $\left.=0.0139\right)(\mathrm{Fig}$. $3 C$ ). No differences were found in the mRNA levels of DGAT1, DGAT2 and MOGAT1 between genotypes (Fig. 3DE).

\section{Discussion}

This is the first study that explores the expression of the enzymes involved in glycerolipid synthesis in different brain structures in two mouse models of leptin action deficiency, insulin resistance and type 2 diabetes but with diverging body adiposity. We focused on the cerebral cortex, hypothalamus, hippocampus and cerebellum because these regions of the brain have the highest abundance of insulin receptor $(24,25)$ and because previous studies have reported lipid composition changes in murine models of IR and T2D states in these regions of the brain (26-29).

We found that hypothalamus was the brain region with the highest abundance of several enzymes (GPAT1, AGPAT1, AGPAT2, AGPAT4, LIPIN1, and MOGAT1) at the mRNA level, suggesting important roles for the glycerolipids in the structure and/or function of this brain regions. Concordantly, it has been shown that glycerolipid metabolism is required for hypothalamic neurons to regulate thermogenesis and energy expenditure in mice (30). Moreover, two of the studied enzymes in our study, LIPIN1 and LIPIN2, seem to have a role in maintaining glycerolipid homeostasis in the mice aging cerebellum. LIPIN2 deficient mice develop ataxia and impaired balance as the mice age, as well as a reduction in cerebellar LIPIN1 levels, resulting in altered cerebellar phospholipid composition (22).

Interestingly, LIPIN2 is expressed in all the brain structures studied, whereas LIPIN1 and MOGAT1 were present mostly in the hypothalamus. These enzymes are essential to generate diacylglycerol, a lipid that has a key role in brain signaling. It has been shown that diacylglycerol participates in synapse plasticity, modulating exocytosis, cytoskeletal reorganization, traffic, and polarization (31). Although these antecedents suggest a role for diacylglycerol generating enzymes in the brain, these actions remain formally unknown.

AGPAT4 was previously reported as the most abundant AGPAT isoform in whole mouse brain preparations (32) and its mRNA was detectable at similar levels between brain stem, cerebellum, cortex, hippocampus and olfactory bulb in mice (33). Agpat4 $^{-/-}$mice have impaired spatial learning and memory, in association with drastically decreased NMDA and AMPA receptor levels in the brain (34). On 
the other hand, AGPAT4 is involved in phosphatidylcholine, phosphatidylethanolamine and phosphatidylinositol synthesis in the brain (33); however, whether phospholipid alterations are connected to the neurological defects of the AGPAT4 deficient mice remains to be elucidated. Similarly, a recent study suggests that AGPAT1 can have roles in neuronal function, since Agpat1 ${ }^{-/-}$mice have abnormal hippocampal neuron development and develop audiogenic seizures (35).

The role of AGPAT2 in brain lipid composition and function has not been systematically studied. Previous studies have shown that AGPAT2 is expressed in the cerebral cortex, spinal cord, medulla, and subthalamic nucleus of the human brain (36). However, patients with congenital generalized lipodystrophy owed to mutations in AGPAT2 gene $(37,38)$ and Agpat2 ${ }^{-/-}$mice $(9)$ have no clinically evident neurological defects, suggesting that AGPAT2 is disposable for brain functions. By contrast, neurological alterations analogous to those present in patients with schizophrenia, depression and Alzheimer's disease have been reported in $\operatorname{Lep} \mathrm{rb}^{\mathrm{db} / \mathrm{db}}$ mice $(39,40)$. In addition, these mice have an accelerated cognitive decline, that starts at 7 weeks of life (41-43). Provocatively, abnormal levels of proteins involved in energy metabolism, cellular structure and neural functioning have been described in the frontal cortex and hippocampus of $L e p r^{\mathrm{db} / \mathrm{db}}$ mice (40), indicating that abnormal metabolic regulation is correlated with abnormal neurological function in these animals. It remains to be determined whether subclinical manifestations of neurological dysfunction are present in the lipodystrophic Agpat2 ${ }^{-1-}$ mice, and likely in lipodystrophic patient with mutations in AGPAT2, and if so whether these potential alterations are correlated with changes in glycerolipid metabolism.

In spite of the neurological disorders of the $L e p r^{\mathrm{db} / \mathrm{db}}$ mice, we only found fewer and milder changes in the expression of glycerolipid enzymes: only LIPIN1 and GPAT1 were slightly increased in the cerebellum while AGPAT3 was increased in the hypothalamus (Fig. 3). By contrast, in the Agpat2 ${ }^{-1-}$ mice, GPAT1, AGPAT3, AGPAT4 and MOGAT1 mRNA levels were lower in the hypothalamus, whereas MOGAT1 was lower in the cerebral cortex and cerebellum, and AGPAT3 was lower in the hippocampus. LIPIN1 mRNA was increased in all studied brain structures in the Agpat2 ${ }^{-1-}$ mice (Fig. 2). Importantly, the animal models used in this paper do not allow to dissect the contribution of IR, T2D and insufficient leptin action on the abnormal levels of the studied mRNAs. This is because, although both mouse models have a strikingly divergent adiposity phenotype (generalized lipodystrophy vs. morbid obesity), they share several metabolic abnormalities, such as deficiency in leptin action, hyperglycemia, hyperinsulinemia, hepatic steatosis and increased intramyocellular lipid load. The observation that some mRNAs were differentially affected between AGPAT2 deficient and $L e p r^{\mathrm{db} / \mathrm{db}}$ mice, suggest that these could be regulated for factors that diverge between these otherwise metabolically similar mouse models, such as others than leptin adipose tissue-derived hormones.

It is important to notice that different brain structures were not affected equally. This emphasizes the importance of studying brain structures separately rather than whole brain tissue. Hypothalamus was one of the most affected structures, which might be explained by the critical role of the hypothalamus in metabolic regulation, including food intake, energy expenditure, and hepatic glucose production. 
Some reports have described changes in the levels of several lipid species in the brain of murine models of IR and T2D. Sallam et al. found a decrease in total phospholipid levels and an increase in triglyceride (TAG) levels in hippocampal synaptosomes isolated from high fat diet (HFD)-fed AtENPP1-Tg mice (adipocyte-specific ecto-nucleotide pyrophosphate phosphodiesterase overexpressing transgenic mice). These changes were associated with impaired basal synaptic transmission to hippocampal synapses, decreased phosphorylation of the GluN1 glutamate receptor subunit, down-regulation of insulin receptor expression, and up-regulation of the free fatty acids receptor 1 (26). Another study analyzed the effect of T2D induced by a high-fat diet (HFD) on the lipid profiles of the cortex, hippocampus, hypothalamus, and olfactory bulb of the mouse brain. HFD significantly increased diacylglycerol abundance in all analyzed regions. Most phosphatidylserine species were decreased, while lysophosphatidylserine species were substantially increased (27). In the cortex and hippocampus of mice fed with a diet enriched in saturated fatty acids for six months (which induces both IR and T2D), there was an increase in some cholesterolester species and a decrease in some species of phosphatidylcholine and diacylglycerol (28). Rats with streptozotocin-induced diabetes have increased levels of ceramides and some species of sphingomyelin in the prefrontal cortex with possible signaling implications (29).

However, it is important to recognize that in none of these studies is possible to distinguish between diabetes-, HFD-, obesity-, IR- or insulin deficiency-induced changes in brain lipids.

Some of these changes could be related to our results because many of the reported lipids (glycerophospholipids, diacylglycerol, and triglycerides) are synthesized by the enzymes analyzed in our study. Lysophosphatidic acid (LPA) is acylated by 1-acylglycerol-3-phosphate acyltransferases (AGPATs), to form phosphatidic acid (PA), which is the precursor of phosphatidylinositol, phosphatidylglycerol and cardiolipin. The phosphate group of PA is removed by phosphatidic acid phosphatases (mostly belonging to LIPIN family), resulting in diacylglycerol (DAG), a precursor of TAG, and as well as phosphatidylcholine, phosphatidylethanolamine, and phosphatidylserine. Most of the above commented studies show a decline in specific phospholipids in the cortex, hippocampus, and hypothalamus.

The changes observed in the brain of Agpat2 $^{-/-}$mice are in contrast with to those observed in the liver of these mice. In fact, Agpat2 $^{-/-}$mice have increased hepatic abundance of GPAT1, AGPAT1, AGPAT3 and MOGAT1 in comparison with wild type mice (9). In the liver, GPAT1 gene expression is potently induced by insulin by mechanisms involving sterol regulatory element-binding protein-1 (SREBP-1) (8), whereas MOGAT1 expression is promoted by peroxisome proliferator-activated receptor gamma (PPARY) by insulin independent mechanisms (44). The diverging regulation of GPAT1 between these two organs of the Agpat2 $^{-/-}$mice can be explained by a differential effect of IR between the brain and the liver. Alternatively, the mechanisms regulating the expression of these enzymes in the brain might be different than in the liver. A recent study showed that the mRNA levels of AGPAT1-5 in liver, heart and whole brain are induced by fasting in mice (45), suggesting the physiological regulation of these enzymes is influenced by nutritional/metabolic status across different tissues. However, the physiological role of the enzymes involved in the glycerolipid biosynthesis in the brain for the metabolic adaptation to fasting remains totally unknown. 
The results obtained in this work can be an starting point for studies intended to disclose a number of unresolved problems such as: 1) function of the genes involved in glycerolipid synthesis in the brain, considering the very low levels of neutral lipids in this tissue, but the important structural and regulatory functions of the different glycerophospholipids, 2) the regulation of the gene expression of these enzymes in the different areas of the brain, and 3) the role of brain glycerolipids in the general pathophysiology of insulin resistance and neurodegeneration.

Our study suggest that enzymes involved in glycerolipid synthesis have a differential gene expression across brain regions and that leptin, insulin and/or any of the metabolic abnormalities associated with IR have an effect on the expression level of these enzymes.

An important limitation of our work is that is limited to the description of the mRNA levels.

Comprehensive quantitative analyses of the glycerolipids of the different brain regions will represent a major advance in the field of brain lipid metabolism and will shed light on the functional meaning of the results reported by us. We hope that future studies will be able to compare lipid composition in the brain in mouse models of IR and leptin deficiency.

\section{Conclusions}

Herein we found that enzymes involved in glycerolipids synthesis are differentially expressed across regions of the brain in mice; and that two different models of IR and T2D have a differential expression pattern of some of these enzymes in different regions of the brain. $L e p r^{\mathrm{db} / \mathrm{db}}$ had fewer and smaller changes in comparison with the Agpat2-/- mice (Fig. 4) suggesting that the abnormal gene expression in the Agpat2 $^{-/-}$mice is due to specific lipid composition perturbations derived from AGPAT2 deficiency rather than primary general metabolic alterations owed to leptin action deficiency. It remains to be studied whether these mRNA changes have an impact on the abundance of different glycerophospholipids in the brain and its role in brain functioning as a whole-body metabolic regulator.

\section{Abbreviations}

\section{AGPAT}

1-acylglycerol-3-phosphate acyltransferase

\section{AMPA}

$\left[{ }^{3} \mathrm{H}\right]$ a-amino-3-hydroxy-5-methyl-4-isoxazolepropionic acid

DAG

diacylglycerol

DGAT

diacylglycerol acyltransferase

GPAT

glycerol-3-phosphate acyltransferase

IR 
insulin resistance

Lepr

leptin receptor

LPA

lysophosphatidic acid

MOGAT

monoacylglycerol acyltransferase

NMDA

$\left[{ }^{3} \mathrm{H}\right]$ glutamate binding to $\mathrm{N}$-methyl-D-aspartate

PA

phosphatidic acid

PAP

phosphatidic acid phosphatase

Ppib

cyclophilin

PS

phosphatidylserine

RT-qPCR

reverse transcription real time PCR

T2D

type 2 diabetes

TAG

triacylglycerol

\section{Declarations}

\section{Ethics approval and consent to participate}

All mouse procedures were reviewed and approved by the Institutional Animal Care and Use Committee (IACUC) at Pontificia Universidad Católica de Chile (ID 170717017).

\section{Consent for publication}

Not applicable

\section{Availability of data and materials}

The datasets used and/or analyzed during the current study are available from the corresponding author on reasonable request.

\section{Competing interests}


The authors declare that they have no competing interests.

\section{Funding}

This work was supported by FONDECYT (Fondo Nacional de Desarrollo Científico y Tecnológico) [grant number 1181214].

\section{Authors' contributions}

V.C. designed and wrote the grant. L.G. designed specific aims and experiments of the study; performed the experiments and the analysis and interpretation of the data under the guidance of V.C. A.K.A. critically revised and contributed to the manuscript. The manuscript was written by L.G. and V.C.

\section{Acknowledgements}

The authors thank to A. Garg and J.D. Horton from UT Southwestern for providing the AGPAT2 deficient mice under the material transfer agreement with Pontificia Universidad Católica de Chile and for their continual scientific advice. We also thank to Dolores Busso for providing the $L e p r^{\mathrm{db} / \mathrm{db}}$ mice.

\section{References}

1. Sato N, Morishita R. Brain alterations and clinical symptoms of dementia in diabetes: $A \beta$ / taudependent and independent mechanisms. Front Endocrinol (Lausanne). 2014;5(September):1-8.

2. Thiebaud N, Johnson MC, Butler JL, Bell GA, Ferguson KL, Fadool AR, et al. Hyperlipidemic Diet Causes Loss of Olfactory Sensory Neurons, Reduces Olfactory Discrimination , and Disrupts OdorReversal Learning. J Neurosci. 2014;34(20):6970-84.

3. Farooqui AA, Horrocks LA, Farooqui T. Glycerophospholipids in brain - their metabolism, incorporation into membranes, functions, and involvement in neurological disorders. Chem Phys Lipids. 2000;106:1-29.

4. Gagné J, Giguère C, Tocco G, Ohayon M, Thompson RF, Baudry M, et al. Effect of phosphatidylserine on the binding properties of glutamate receptors in brain sections from adult and neonatal rats. Brain Res. 1996;740(1-2):337-45.

5. Camargo N, Smit AB, Verheijen MHG. SREBPs: SREBP function in glia-neuron interactions. FEBS J. 2009;276(3):628-36.

6. Coleman RA, Lee DP. Enzymes of triacylglycerol synthesis and their regulation. Prog Lipid Res. 2004;43(2):134-76.

7. Agarwal AK, Garg A. Congenital generalized lipodystrophy: Significance of triglyceride biosynthetic pathways. Trends Endocrinol Metab. 2003;14(5):214-21.

8. Takeuchi K, Reue K. Biochemistry, physiology, and genetics of GPAT, AGPAT, and lipin enzymes in triglyceride synthesis. Am J Physiol Endocrinol Metab [Internet]. 2009;296(6):E1195-209. Available 
from: http://www.pubmedcentral.nih.gov/articlerender.fcgi?

artid $=2692402 \&$ tool $=$ pmcentrez\&rendertype $=$ abstract

9. Cortés VA, Curtis DE, Sukumaran S, Shao X, Parameswara V, Rashid S, et al. Molecular mechanisms of hepatic steatosis and insulin resistance in the AGPAT2-deficient mouse model of congenital generalized lipodystrophy. Cell Metab [Internet]. 2009 Feb [cited 2016 Nov 30];9(2):165-76. Available from: http://linkinghub.elsevier.com/retrieve/pii/S1550413109000035

10. Cortés VA, Cautivo KM, Rong S, Garg A, Horton JD, Agarwal AK. Leptin ameliorates insulin resistance and hepatic steatosis in Agpat2-/-lipodystrophic mice independent of hepatocyte leptin receptors. J Lipid Res. 2014;55(2):276-88.

11. Chen $\mathrm{H}$, Charlat $\mathrm{O}$, Tartaglia LA, Woolf EA, Weng X, Ellis SJ, et al. Evidence That the Diabetes Gene Encodes the Leptin Receptor: Identification of a Mutation in the Leptin Receptor Gene in $\mathrm{db} / \mathrm{db}$ Mice. Cell. 1996;84(3):491-5.

12. King AJF. The use of animal models in diabetes research. Br J Pharmacol. 2012;166(3):877-94.

13. Kobayashi K, Forte TM, Taniguchi S, Ishida BY, Oka K, Chan L. The db/db Mouse, a Model for Diabetic Dyslipidemia: Molecular Characterization and Effects of Western Diet Feeding. Metabolism. 2000;49(1):22-31.

14. Ghasemi A, Zahediasl S. Normality Tests for Statistical Analysis: A Guide for Non-Statisticians. Endocrinol Metab. 2012;10(2):486-9.

15. Oztuna D, Elhan DA, Tuccar E. Investigation of Four Different Normality Tests in Terms of Type 1 Error Rate and Power under Different Distributions. Turk J Med Sci. 2006;36(3):171-6.

16. Koch AL. The Logarithm in Biology. J Theor Biol. 1966;12:276-90.

17. Limpert E, Stahel WA, Abbt M. Log-normal Distributions across the Sciences: Keys and Clues. Bioscience. 2001;51(5):341-52.

18. Healy MJR. Data transformations. Arch Dis Child. 1993;69:260-4.

19. Bland JM, Altman DG. Transforming data. BMJ. 1996;312:770.

20. Bland JM, Altman DG. The use of transformation when comparing two means. BMJ. 1996;312:1153.

21. Feng C, Wang H, Lu N, Tu XM. Log transformation: application and interpretation in biomedical research. Stat Med. 2013;32(2):230-9.

22. Dwyer JR, Donkor J, Zhang P, Csaki LS, Vergnes L, Lee JM, et al. Mouse lipin-1 and lipin-2 cooperate to maintain glycerolipid homeostasis in liver and aging cerebellum. Proc Natl Acad Sci [Internet]. 2012 Sep 11 [cited 2016 Dec 5];109(37):E2486-95. Available from: http://www.ncbi.nlm.nih.gov/pubmed/22908270

23. Wang H, Zhang J, Qiu W, Han G-S, Carman GM, Khosrow A. Lipin-1 gamma isoform is a novel lipid droplet-associated protein highly expressed in the brain. FEBS Lett. 2011;585(12):1979-84.

24. Unger JW, Livingston JN, Moss AM. Insulin receptors in the central nervous system: localization, signalling mechanisms and functional aspects. Prog Neurobiol [Internet]. 1991;36(5):343-62. 
Available from: http://www.ncbi.nlm.nih.gov/entrez/query.fcgi?

cmd=Retrieve\&db=PubMed\&dopt=Citation\&list_uids $=1887067$

25. Hopkins DFC, Williams G. Insulin receptors are widely distributed in human brain and bind human and porcine insulin with equal affinity. Diabet Med. 1997;14(12):1044-50.

26. Hanaa S. Sallam, Batbayar Tumurbaatar, Wen-Ru Zhang, Demidmaa Tuvdendorj, Manisha Chandalia, Filippo Tempia, Fernanda Laezza, Giulio Taglialatela NA. Peripheral adipose tissue insulin resistance alters lipid composition and function of hippocampal synapses. J Neurochem. 2015;133(1):125-33.

27. Cheol J, Mi S, Yong I, Sung H, Kyung J. High-fat diet-induced lipidome perturbations in the cortex, hippocampus, hypothalamus, and olfactory bulb of mice. BBA - Mol Cell Biol Lipids [Internet]. 2018;1863(9):980-90. Available from: https://doi.org/10.1016/j.bbalip.2018.05.007

28. Giles C, Takechi R, Mellett NA, Meikle PJ, Dhaliwal S, Mamo JC. The Effects of Long-Term Saturated Fat Enriched Diets on the Brain Lipidome. PLoS One. 2016;11(12):e0166964.

29. Fiedorowicz A, Prokopiuk S, Zendzian-Piotrowska M, Chabowski A, Car H. Sphingolipid profiles are altered in prefrontal cortex of rats under acute hyperglycemia. Neuroscience. 2014;256:282-91.

30. Prentki M, Madiraju SRM. Glycerolipid Metabolism and Signaling in Health and Disease. Endocr Rev [Internet]. 2008 Oct [cited 2016 Dec 5];29(6):647-76. Available from:

http://press.endocrine.org/doi/10.1210/er.2008-0007

31. Almena M, Merida I. Shaping up the membrane: diacylglycerol coordinates spatial orientation of signaling. Trends Biochem Sci. 2011;36(11):593-603.

32. Eto M, Shindou H, Shimizu T. A novel lysophosphatidic acid acyltransferase enzyme (LPAAT4) with a possible role for incorporating docosahexaenoic acid into brain glycerophospholipids. Biochem Biophys Res Commun [Internet]. 2014;443(2):718-24. Available from: http://dx.doi.org/10.1016/j.bbrc.2013.12.043

33. Bradley RM, Marvyn PM, Aristizabal Henao JJ, Mardian EB, George S, Aucoin MG, et al. Acylglycerophosphate acyltransferase 4 (AGPAT4) is a mitochondrial lysophosphatidic acid acyltransferase that regulates brain phosphatidylcholine, phosphatidylethanolamine, and phosphatidylinositol levels. Biochim Biophys Acta - Mol Cell Biol Lipids [Internet]. 2015;1851(12):1566-76. Available from: http://dx.doi.org/10.1016/j.bbalip.2015.09.005

34. Bradley RM, Mardian EB, Bloemberg D, Henao JJA, Mitchell AS, Marvyn PM, et al. Mice Deficient in lysophosphatidic acid acyltransferase delta (Lpaatd)/acylglycerophosphate acyltransferase 4 (Agpat4) Have Impaired Learning and Memory. Mol Cell Biol. 2017;37(22):1-17.

35. Agarwal AK, Tunison K, Dalal JS, Nagamma SS, Hamra FK, Sankella S, et al. Metabolic, reproductive, and neurologic abnormalities in Agpat1-Null Mice. Endocrinology. 2017;158(11):3954-73.

36. Eberhardt C, Gray PW, Tjoelker LW. Human lysophosphatidic acid acyltransferase. J Biol Chem [Internet]. 1997;272(32):20299-305. Available from: http://www.jbc.org/content/272/32/20299.abstract 
37. Agarwal AK, Simha V, Oral EA, Moran SA, Gorden P, O'Rahilly S, et al. Phenotypic and Genetic Heterogeneity in Congenital Generalized Lipodystrophy. J Clin Endocrinol Metab. 2003;88(10):48407.

38. Cortés V a., Smalley S V., Goldenberg D, Lagos CF, Hodgson MI, Santos JL. Divergent metabolic phenotype between two sisters with congenital generalized lipodystrophy due to double AGPAT2 homozygous mutations. A clinical, genetic and in silico study. PLoS One. 2014;9(1):1-6.

39. Ajaykumar N. Sharma, Khalid M. Elased, Teresa L. Garrett JBL. Neurobehavioral deficits in db/db diabetic mice. Physiol Behav. 2010;101(3):381-8.

40. Ernst A, Sharma AN, Elased KM, Guest PC, Rahmoune H, Bahn S. Diabetic db / db mice exhibit central nervous system and peripheral molecular alterations as seen in neurological disorders. Transl Psychiatry [Internet]. 2013;3(5):e263-7. Available from: http://dx.doi.org/10.1038/tp.2013.42

41. Li X, Aou S, Oomura ÃY, Hori N, Fukunaga K, Hori T. Impairment of long-term potentiation and spatial memory in leptin receptor-deficient rodents. Neuroscience. 2002;113(3):607-15.

42. Dinel A, Andre C, Agnes A, Ferreira G, Laye S, Castanon N. Cognitive and Emotional Alterations Are Related to Hippocampal Inflammation in a Mouse Model of Metabolic Syndrome. PLoS One. 2011;6(9):e24325.

43. Zheng H, Zheng Y, Zhao L, Chen M, Bai G, Hu Y, et al. Cognitive decline in type 2 diabetic $\mathrm{db} / \mathrm{db}$ mice may be associated with brain region-specific metabolic disorders. BBA - Mol Basis Dis [Internet]. 2017;1863(1):266-73. Available from: http://dx.doi.org/10.1016/j.bbadis.2016.11.003

44. Yu JH, Lee YJ, Kim HJ, Choi H, Choi Y, Seok JW, et al. Monoacylglycerol O-acyltransferase 1 is regulated by peroxisome proliferator-activated receptor $\gamma$ in human hepatocytes and increases lipid accumulation. Biochem Biophys Res Commun [Internet]. 2015;460(3):715-20. Available from: http://dx.doi.org/10.1016/j.bbrc.2015.03.095

45. Bradley RM, Mardian EB, Moes KA, Duncan RE. Acute Fasting Induces Expression of Acylglycerophosphate Acyltransferase (AGPAT) Enzymes in Murine Liver, Heart, and Brain. Lipids [Internet]. 2017;52(5):457-61. Available from: "http://dx.doi.org/10.1007/s11745-017-4251-4

\section{Figures}


A

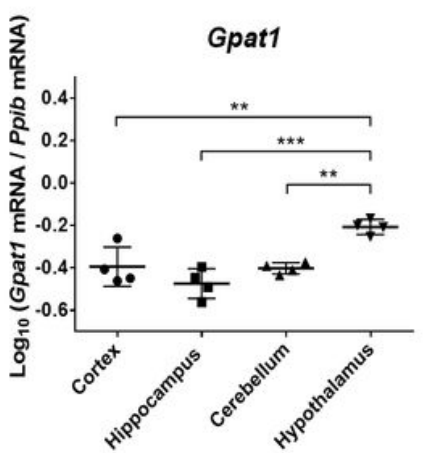

B

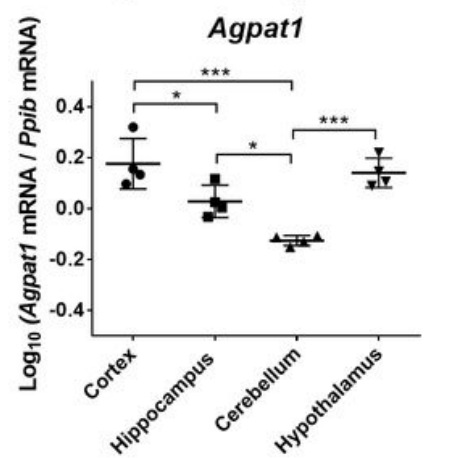

C

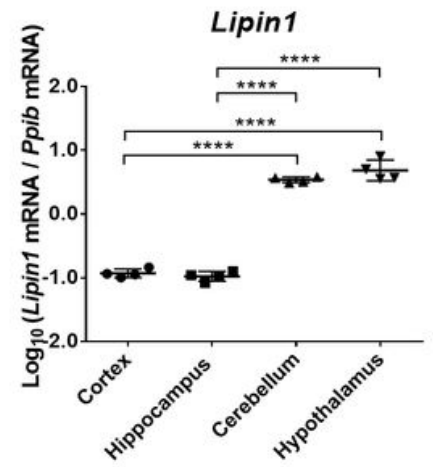

D

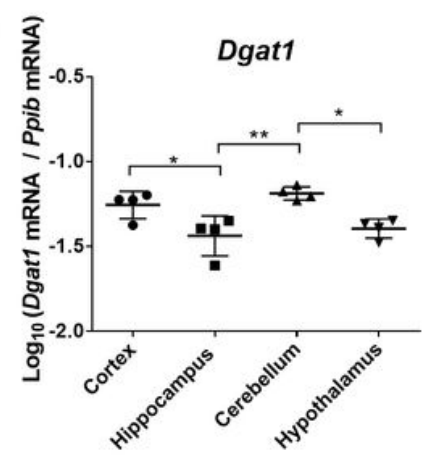

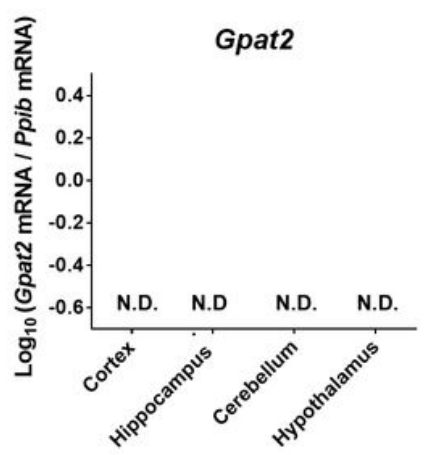
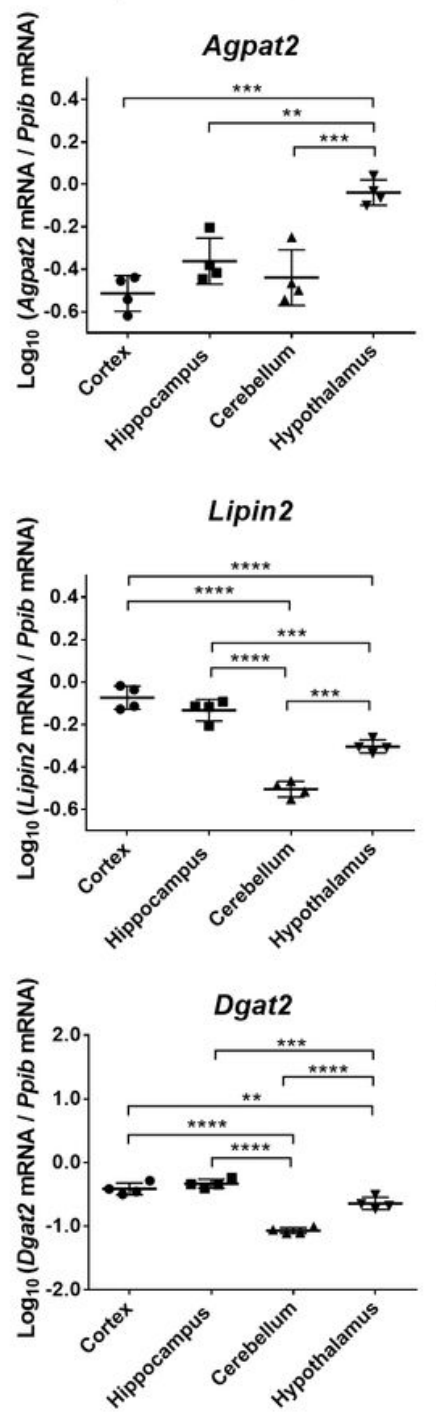
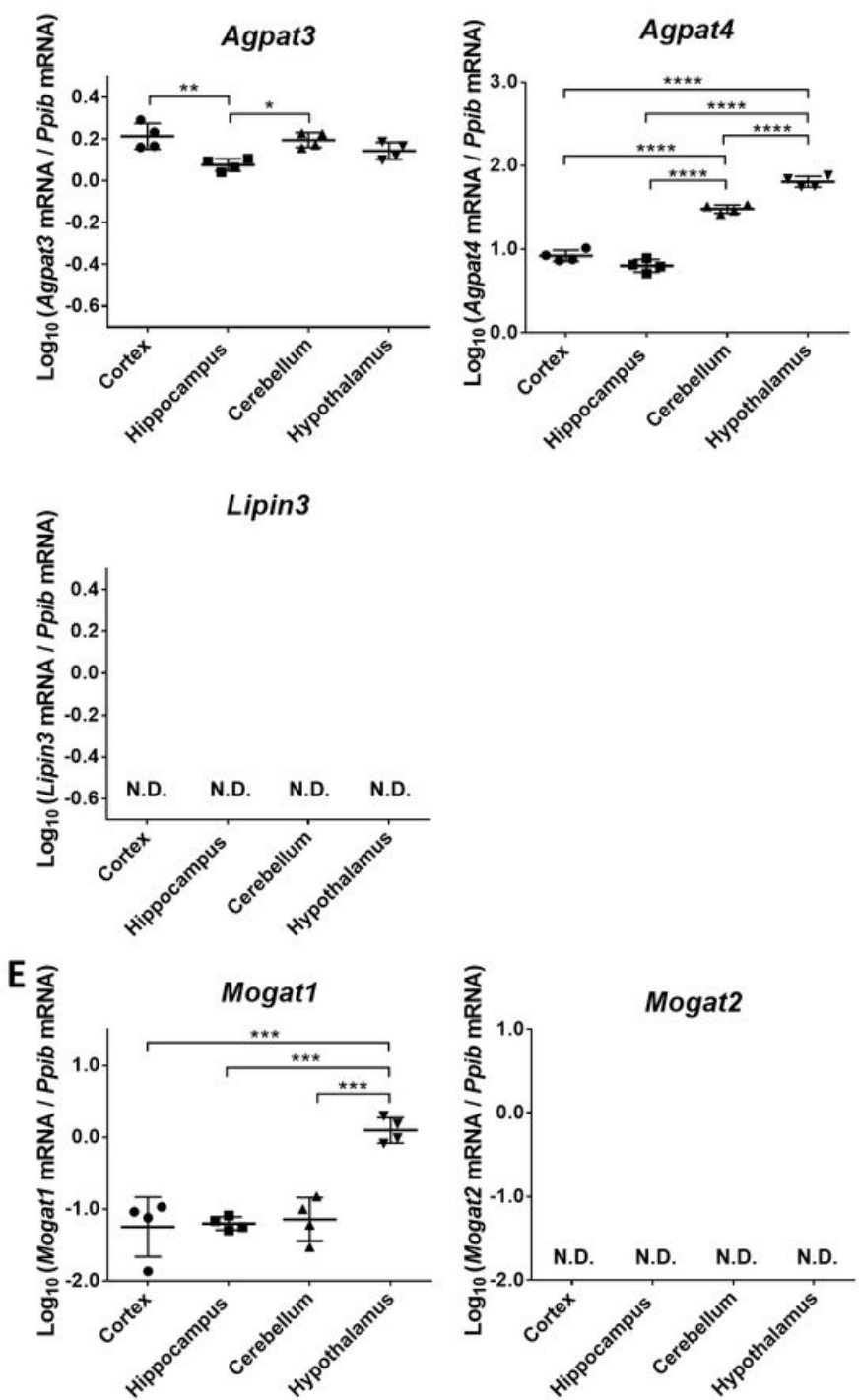

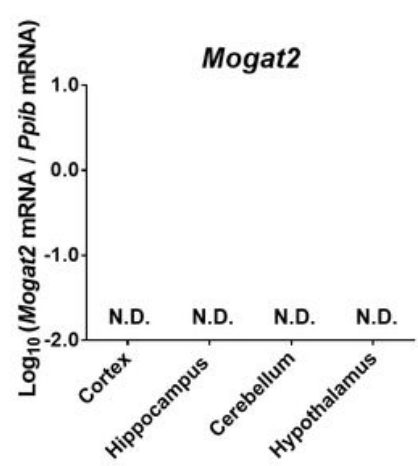

Figure 1

mRNA expression levels of enzymes involved in the glycerolipid synthesis in cerebral cortex, hippocampus, cerebellum and hypothalamus in wild type (C57BL/6) mice. Expression of each gene was normalized to the reference gene Cyclophilin (Ppib) and was calculated by the 2- $\Delta C T$ method (2-(CT target gen - CT reference gen)). Ct value cut off was 30 . Mean values were analyzed by one-way ANOVA and Bonferroni test for multiple comparisons. ${ }^{\star} p<0.05$, ${ }^{\star \star} p<0.01$, ${ }^{\star \star \star} p<0.001$ and ${ }^{\star \star \star \star *} p<0.0001 . n=$ 4 per group (for cortex, cerebellum and hippocampus, there are 2 male and 2 female in each group; for hypothalamus, there are 3 males and 1 female in each group). N.D.: not detected. 
A

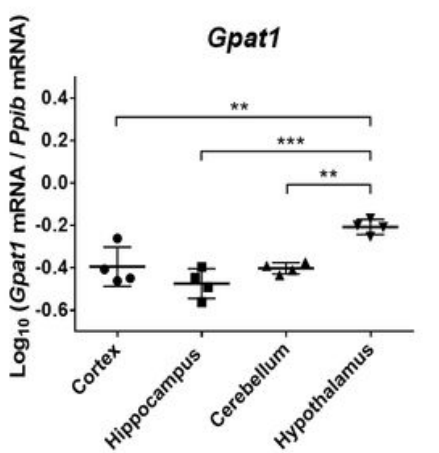

B

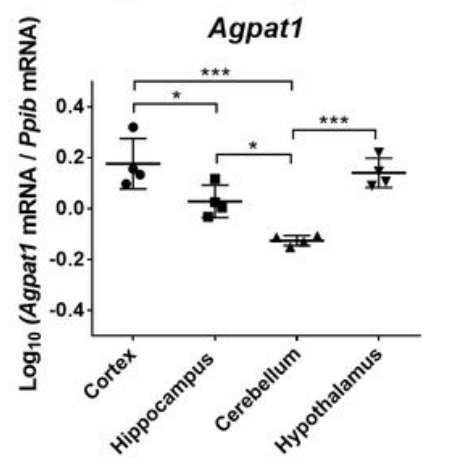

C

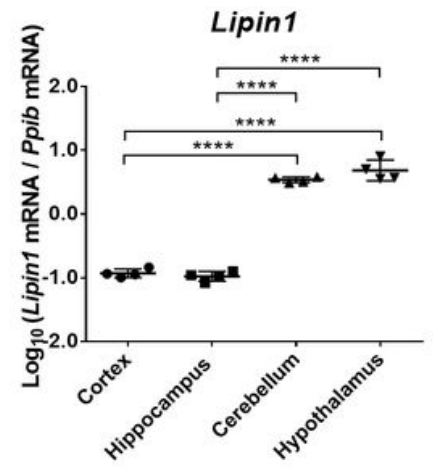

D

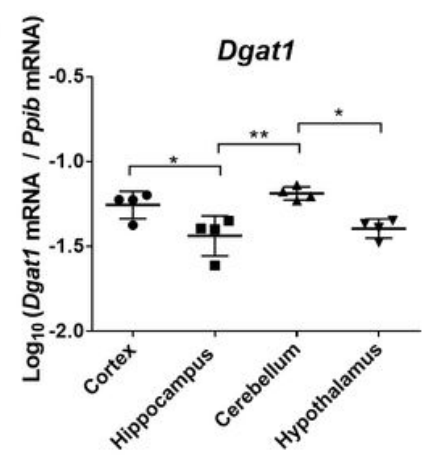

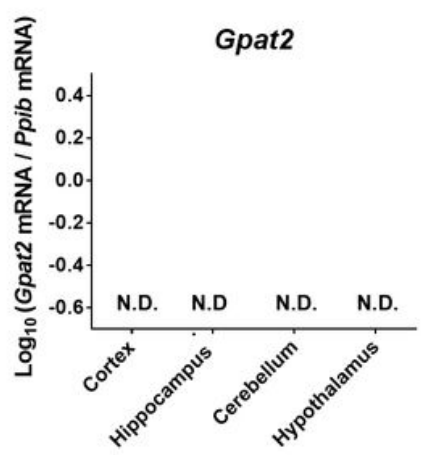
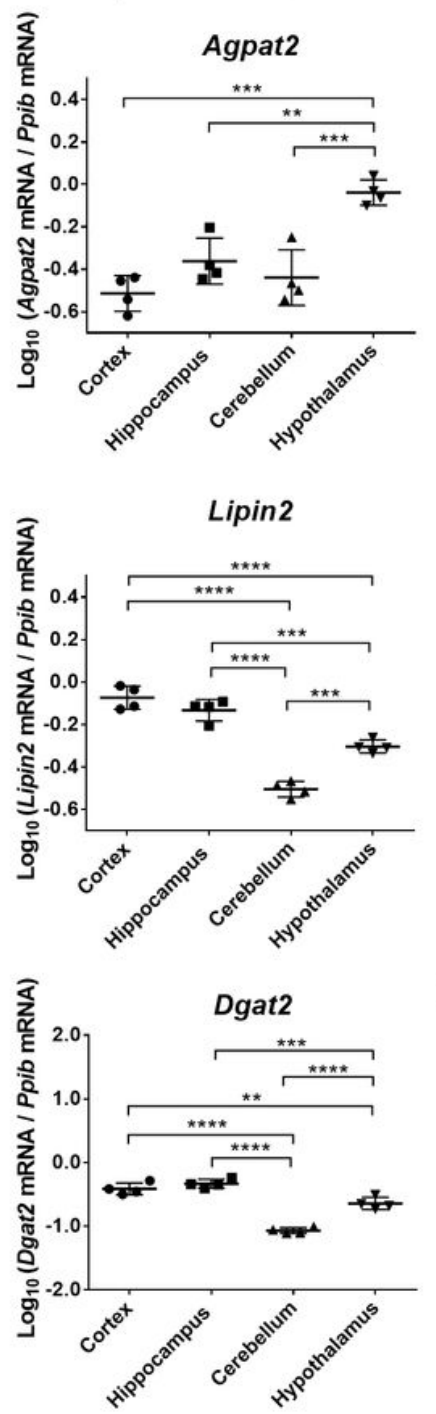
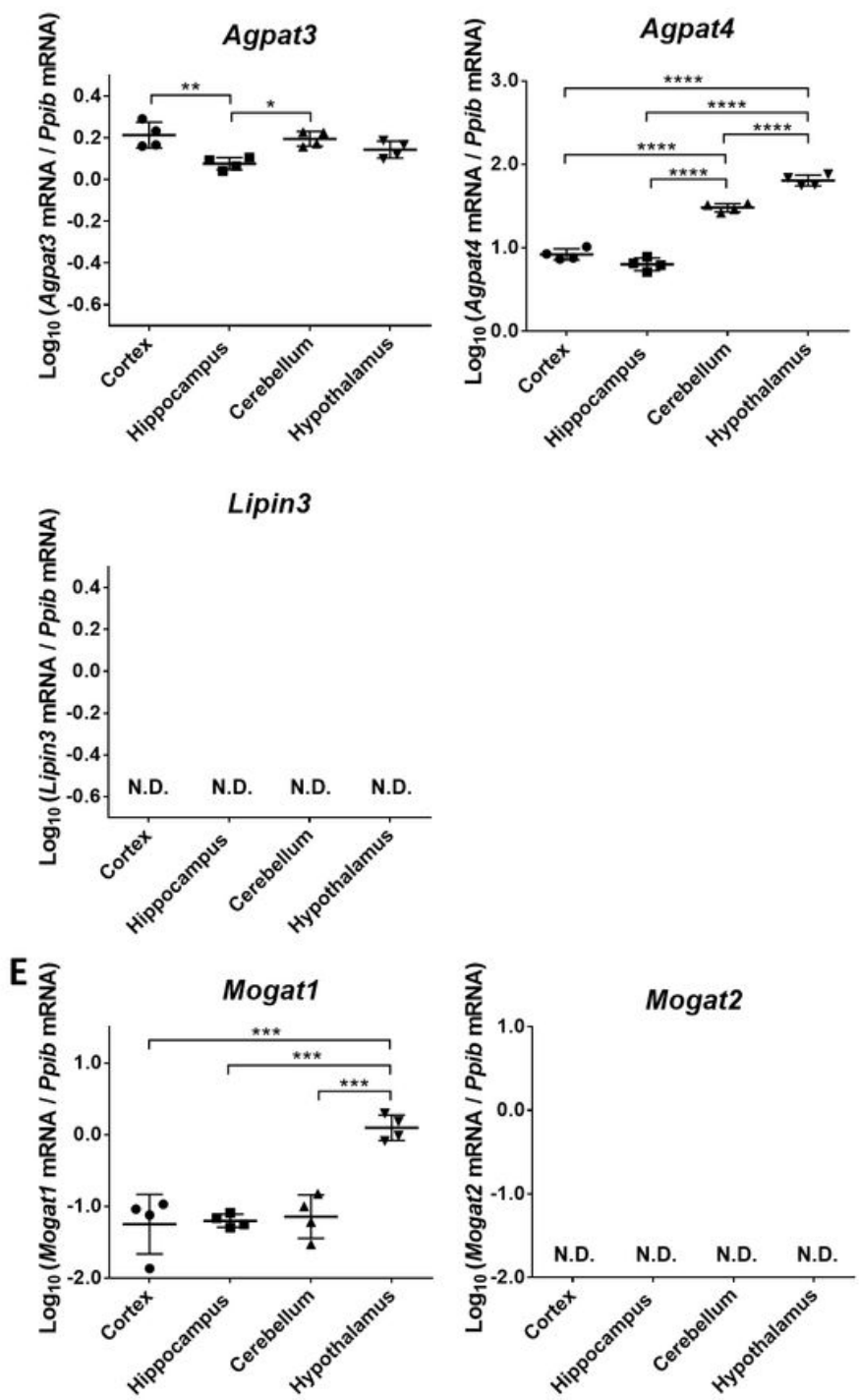

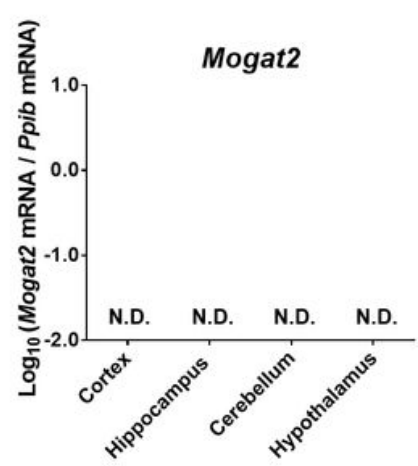

Figure 1

mRNA expression levels of enzymes involved in the glycerolipid synthesis in cerebral cortex, hippocampus, cerebellum and hypothalamus in wild type (C57BL/6) mice. Expression of each gene was normalized to the reference gene Cyclophilin (Ppib) and was calculated by the 2- $\Delta C T$ method (2-(CT target gen - CT reference gen)). Ct value cut off was 30 . Mean values were analyzed by one-way ANOVA and Bonferroni test for multiple comparisons. ${ }^{*} p<0.05$, ${ }^{*} p<0.01$, ${ }^{\star \star *} p<0.001$ and ${ }^{* \star * \star} p<0.0001 . n=$ 4 per group (for cortex, cerebellum and hippocampus, there are 2 male and 2 female in each group; for hypothalamus, there are 3 males and 1 female in each group). N.D.: not detected. 
A

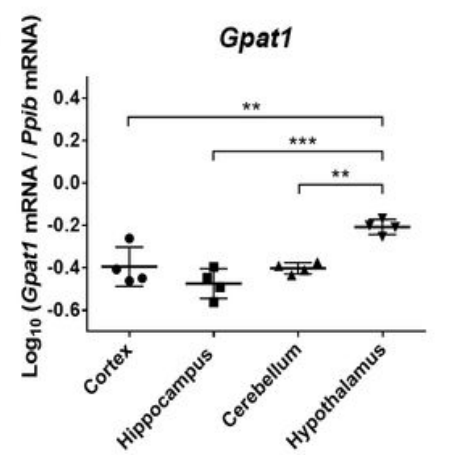

B

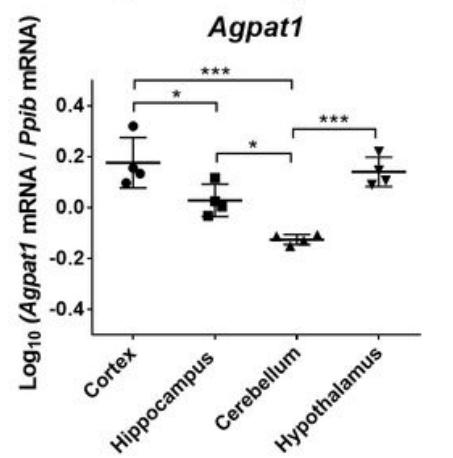

C

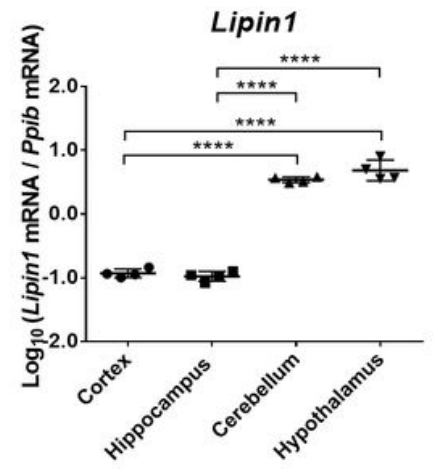

D

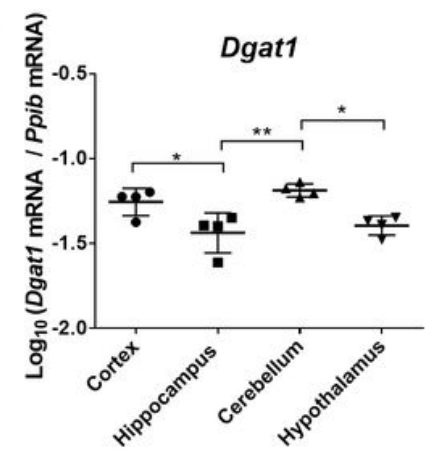

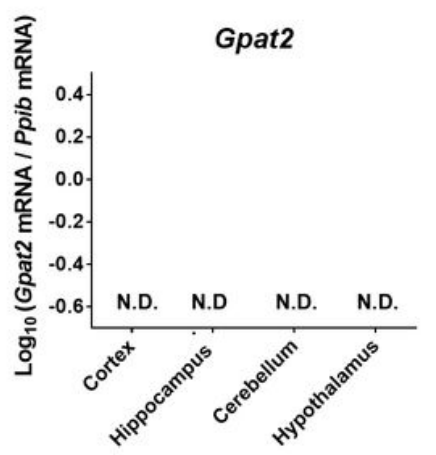
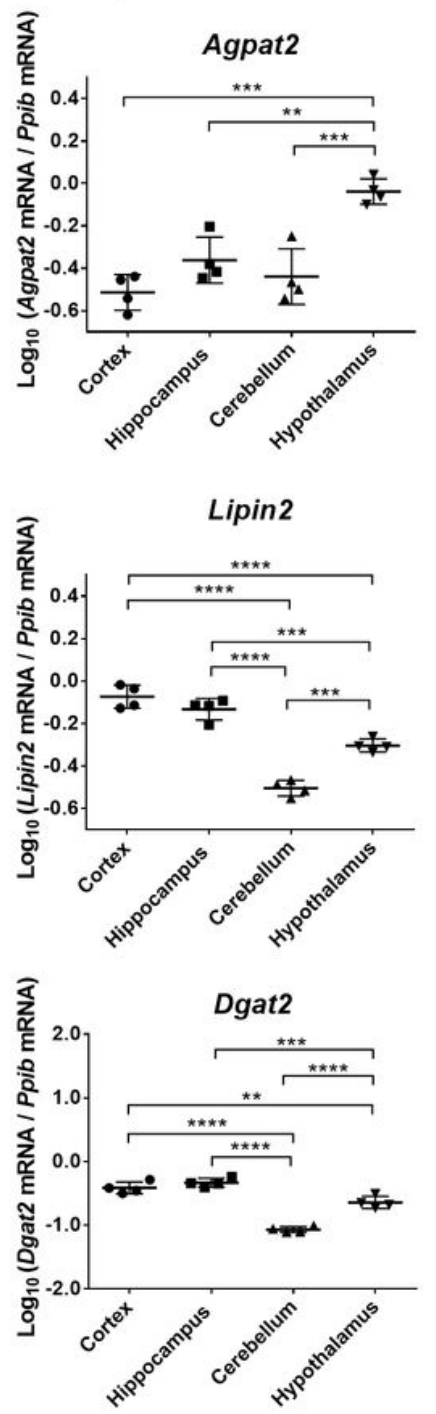
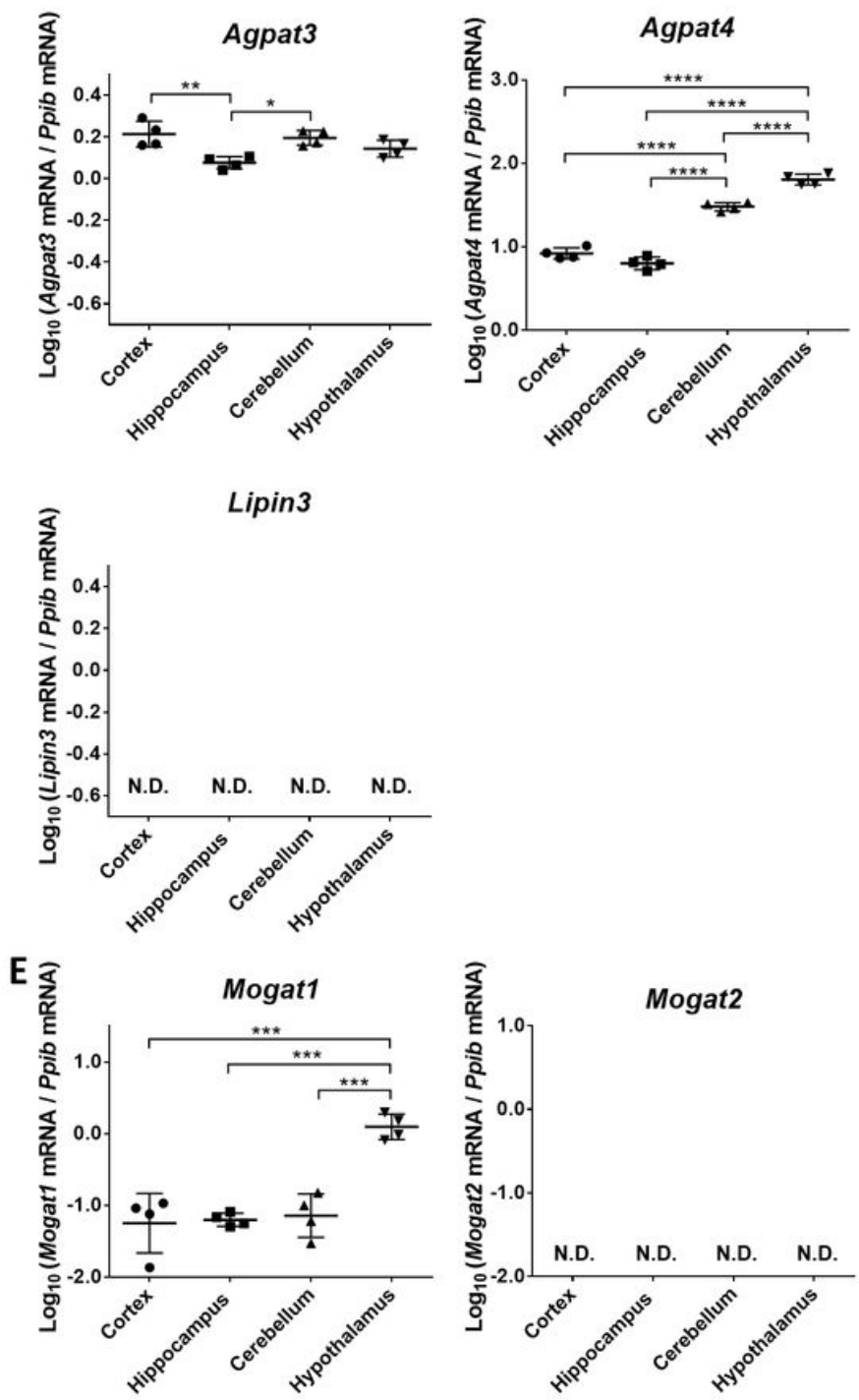

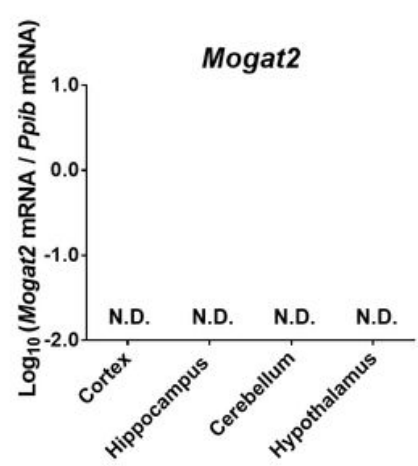

Figure 1

mRNA expression levels of enzymes involved in the glycerolipid synthesis in cerebral cortex, hippocampus, cerebellum and hypothalamus in wild type (C57BL/6) mice. Expression of each gene was normalized to the reference gene Cyclophilin (Ppib) and was calculated by the 2- $\Delta C T$ method (2-(CT target gen - CT reference gen)). Ct value cut off was 30 . Mean values were analyzed by one-way ANOVA and Bonferroni test for multiple comparisons. ${ }^{*} p<0.05$, ${ }^{*} p<0.01$, ${ }^{\star \star *} p<0.001$ and ${ }^{* \star * \star} p<0.0001 . n=$ 4 per group (for cortex, cerebellum and hippocampus, there are 2 male and 2 female in each group; for hypothalamus, there are 3 males and 1 female in each group). N.D.: not detected. 
A

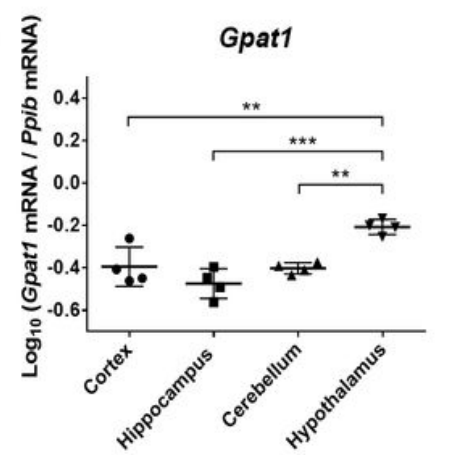

B

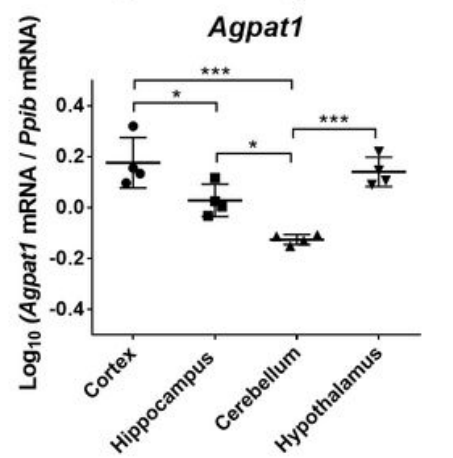

C

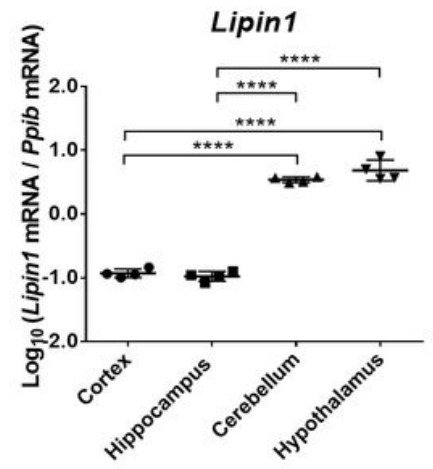

D

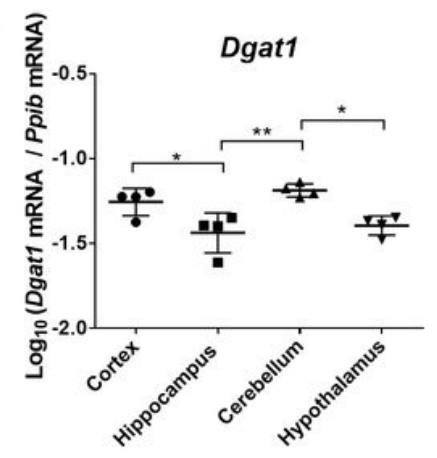

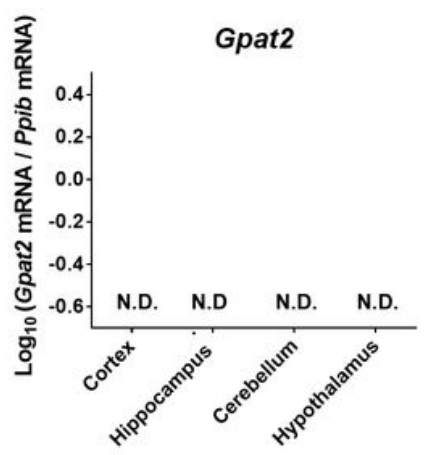
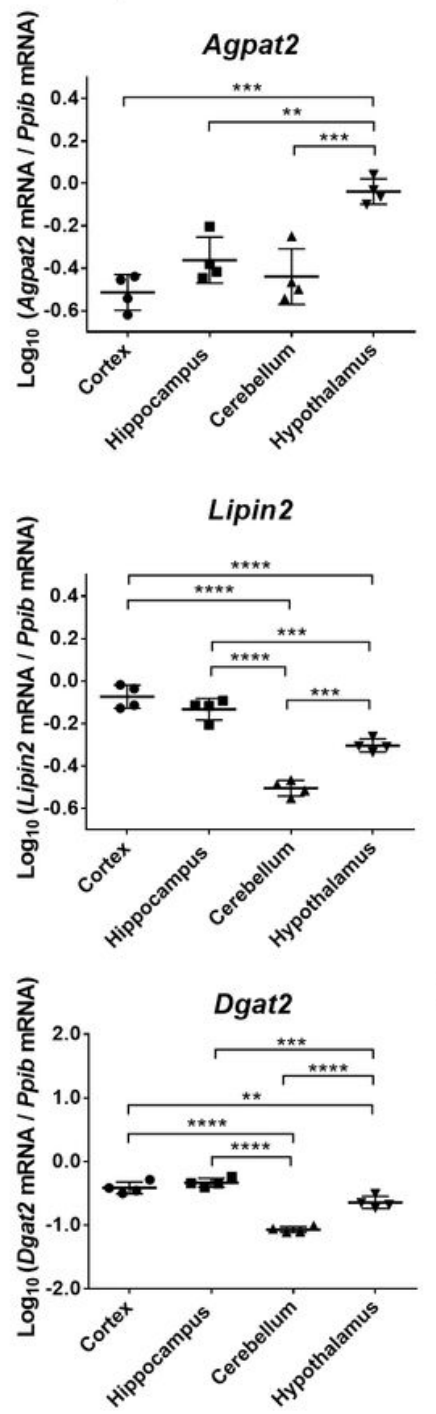
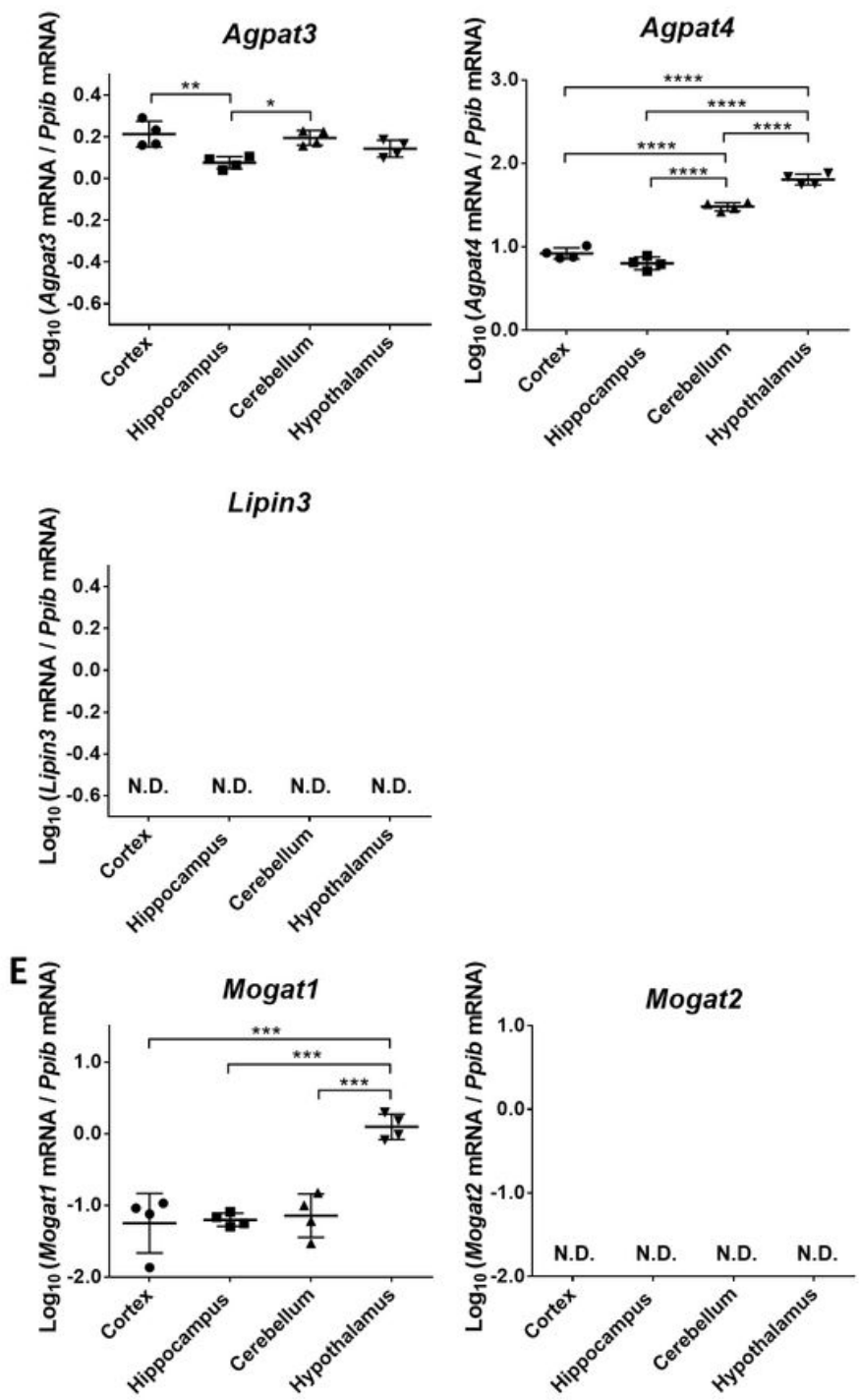

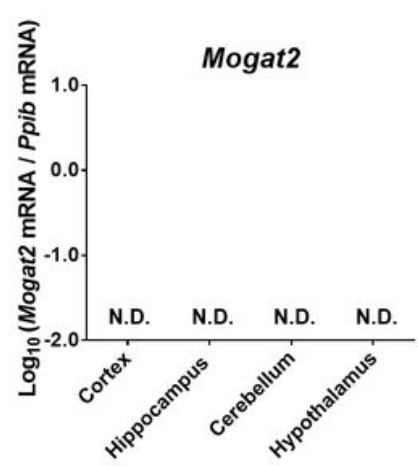

Figure 1

mRNA expression levels of enzymes involved in the glycerolipid synthesis in cerebral cortex, hippocampus, cerebellum and hypothalamus in wild type (C57BL/6) mice. Expression of each gene was normalized to the reference gene Cyclophilin (Ppib) and was calculated by the 2- $\Delta C T$ method (2-(CT target gen - CT reference gen)). Ct value cut off was 30 . Mean values were analyzed by one-way ANOVA and Bonferroni test for multiple comparisons. ${ }^{*} p<0.05$, ${ }^{*} p<0.01$, ${ }^{\star \star *} p<0.001$ and ${ }^{* \star * \star} p<0.0001 . n=$ 4 per group (for cortex, cerebellum and hippocampus, there are 2 male and 2 female in each group; for hypothalamus, there are 3 males and 1 female in each group). N.D.: not detected. 
A

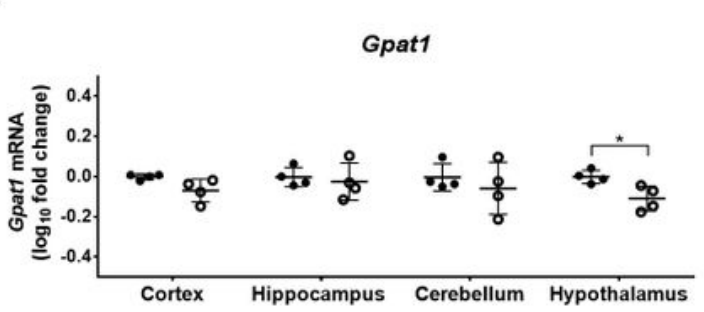

B
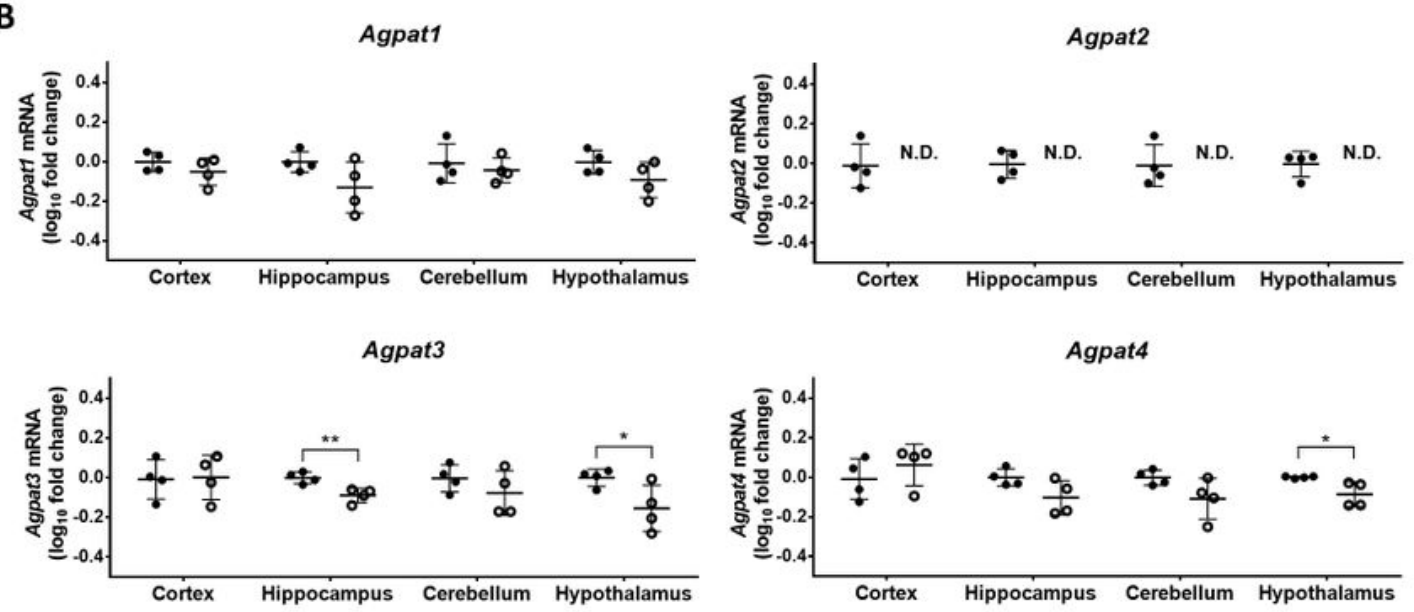

C
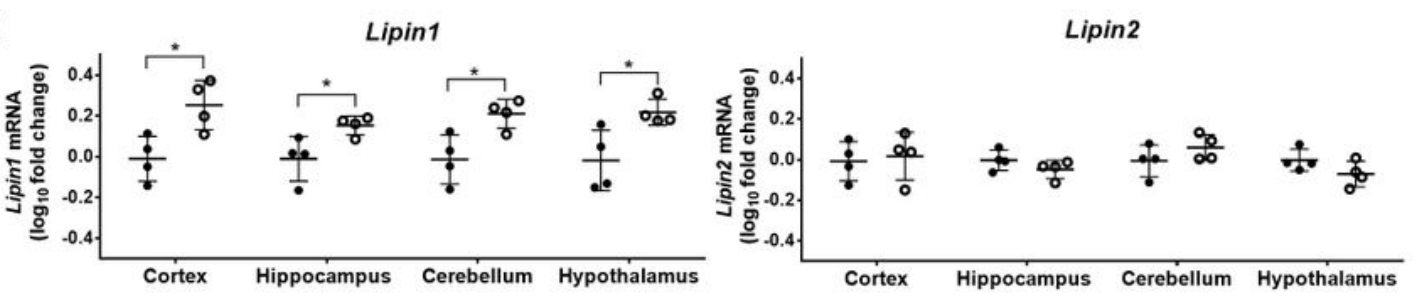

D

Dgat1

Dgat2
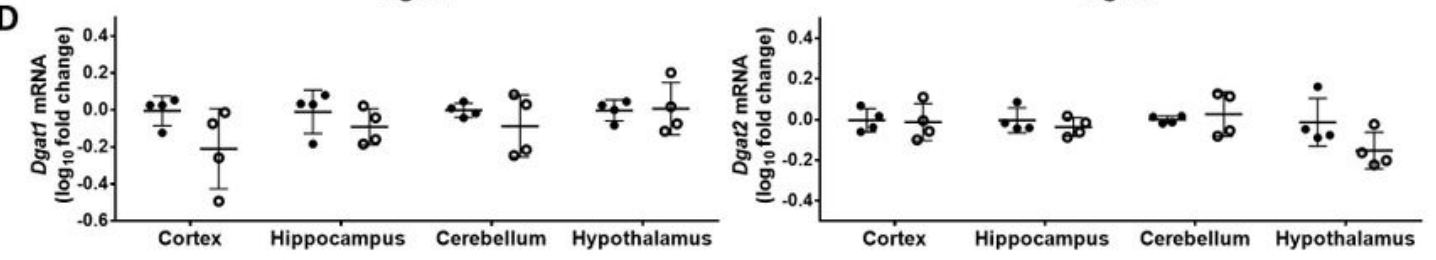

Mogat1

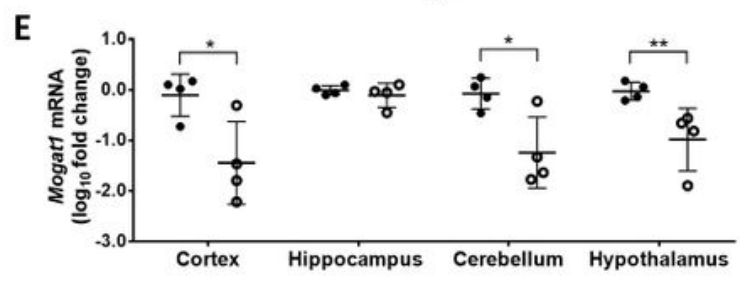

Figure 2

mRNA expression levels of enzymes involved in glycerolipid synthesis in cerebral cortex, hippocampus, cerebellum and hypothalamus of Agpat2+/+ and Agpat2-/- mice. mRNA expression levels of each gene were normalized by Cyclophilin mRNA expression levels and expressed as fold-change compared to wild type (Agpat2+/+) mice, by $2-\Delta \Delta C T$ method. * $p<0.05$, ** $p<0.01$, *** $p<0.001$ and **** $p<0.0001$. Mean values were analyzed by unpaired Student's t test. $n=4$ animals per group (two male and two female per 
group; except for genes measured in the hypothalamus of wild type mice, in which there are 3 males and 1 female per group). N.D.: not detected.

A

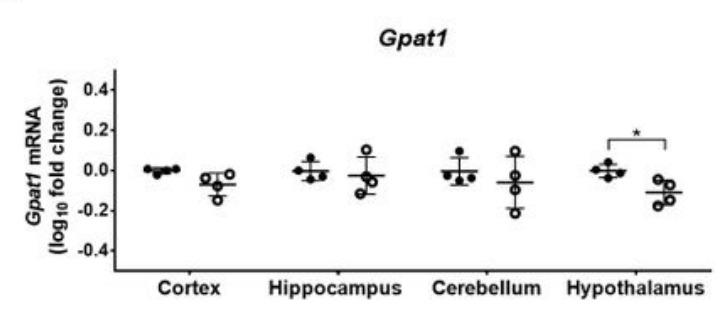

B
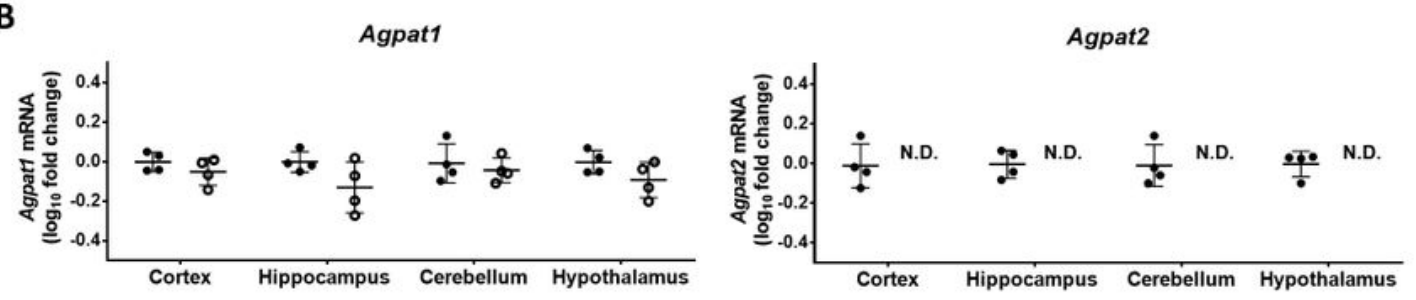

Agpat3

- Agpat2 $2^{+/+}$

- Agpat2\%
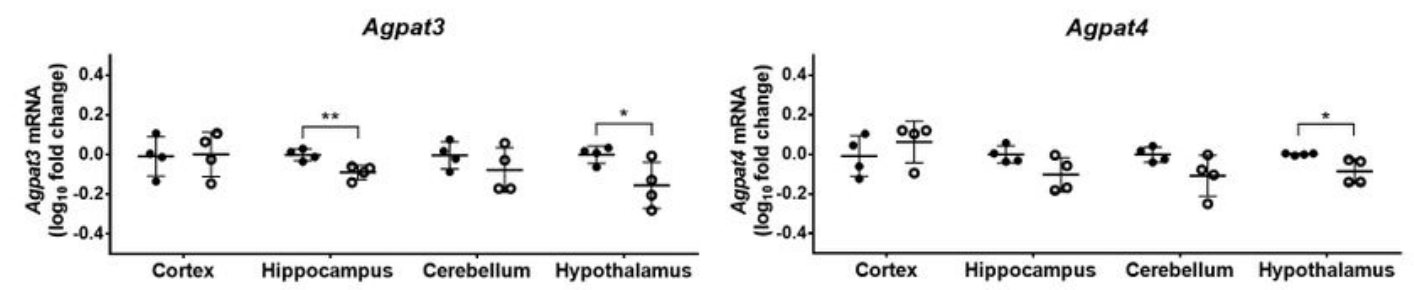

C
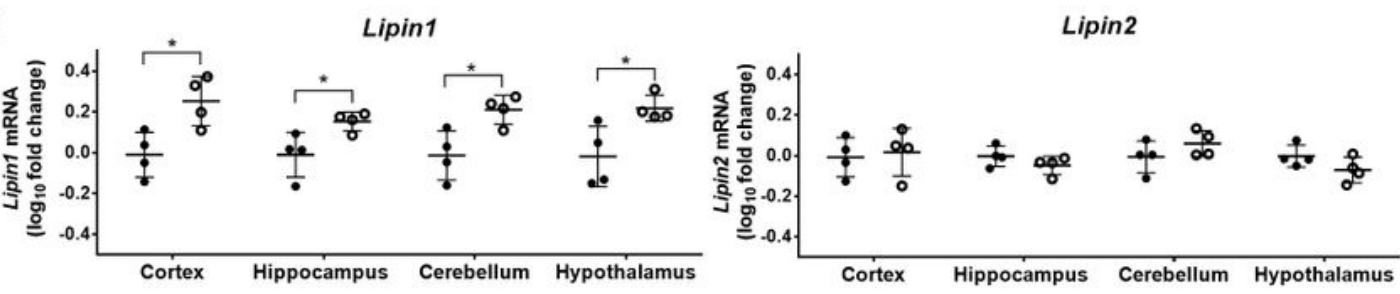

D

Dgat1
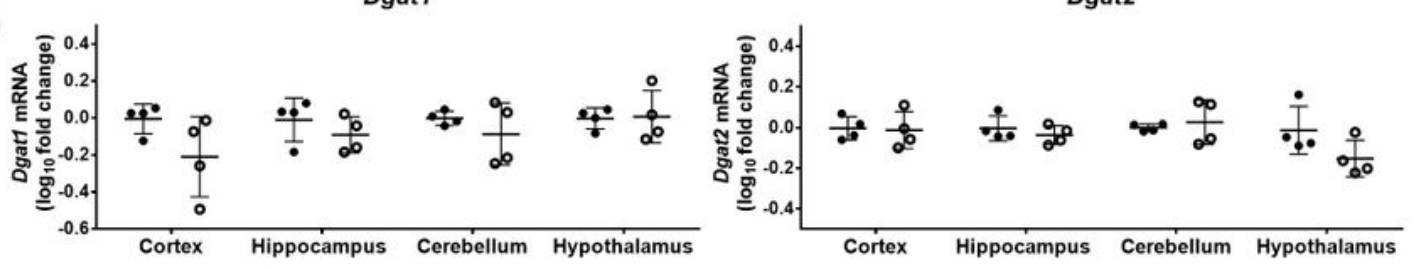

Mogat1

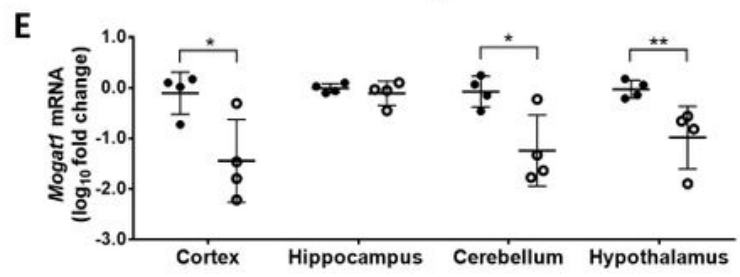

\section{Figure 2}

mRNA expression levels of enzymes involved in glycerolipid synthesis in cerebral cortex, hippocampus, cerebellum and hypothalamus of Agpat2+/+ and Agpat2-/- mice. mRNA expression levels of each gene were normalized by Cyclophilin mRNA expression levels and expressed as fold-change compared to wild 
type (Agpat2+/+) mice, by $2-\Delta \Delta C T$ method. * $p<0.05, * * p<0.01$, *** $p<0.001$ and $* * \star * ~ p<0.0001$. Mean values were analyzed by unpaired Student's t test. $n=4$ animals per group (two male and two female per group; except for genes measured in the hypothalamus of wild type mice, in which there are 3 males and 1 female per group). N.D.: not detected.

A

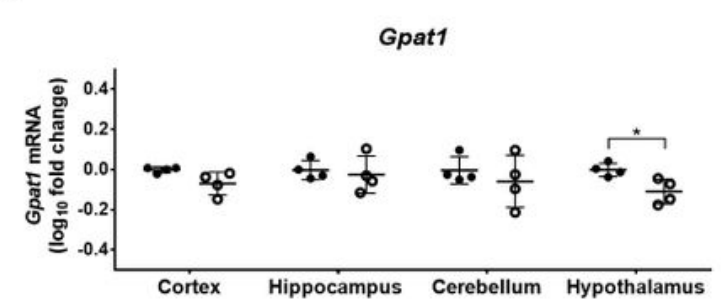

B

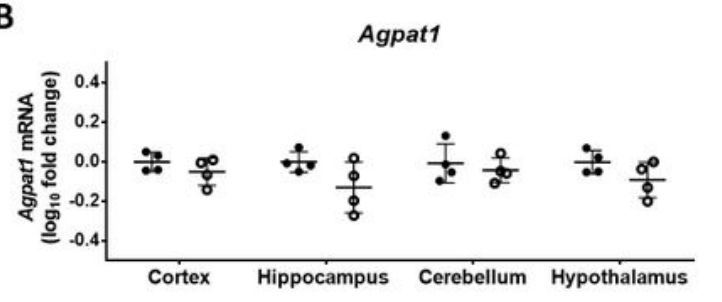

- Agpat $2^{+/+}$
- Agpat $2 \%$

Agpat3
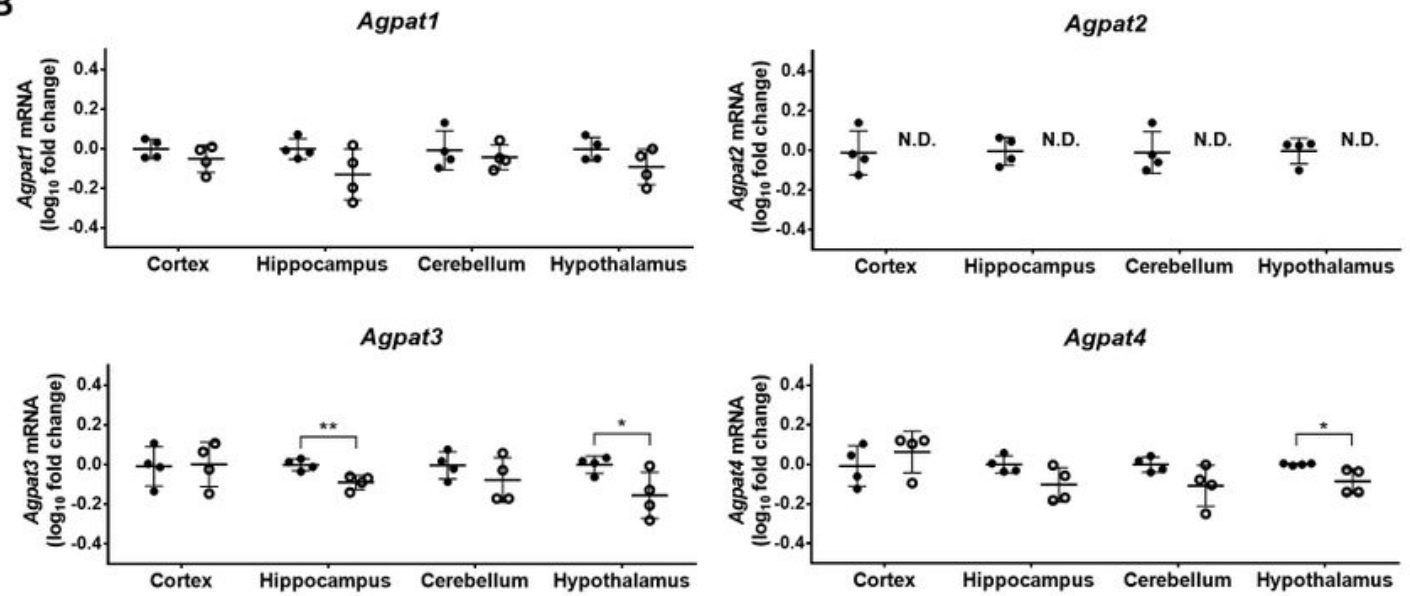

C
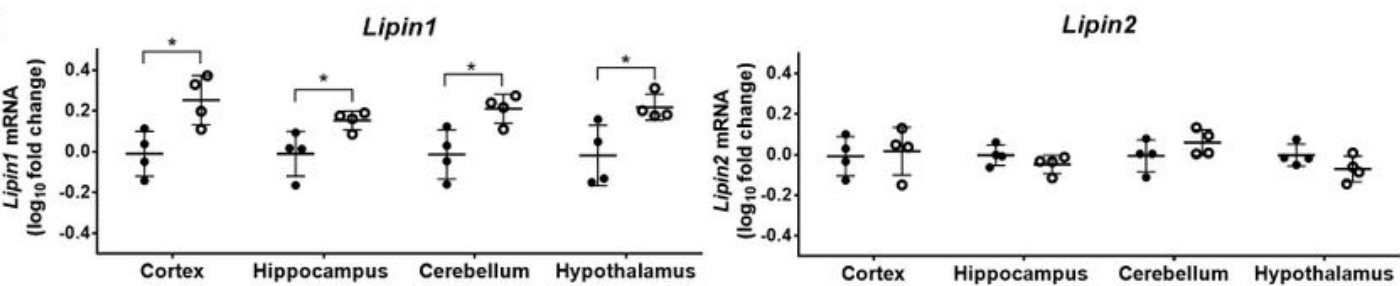

Dgat1

D
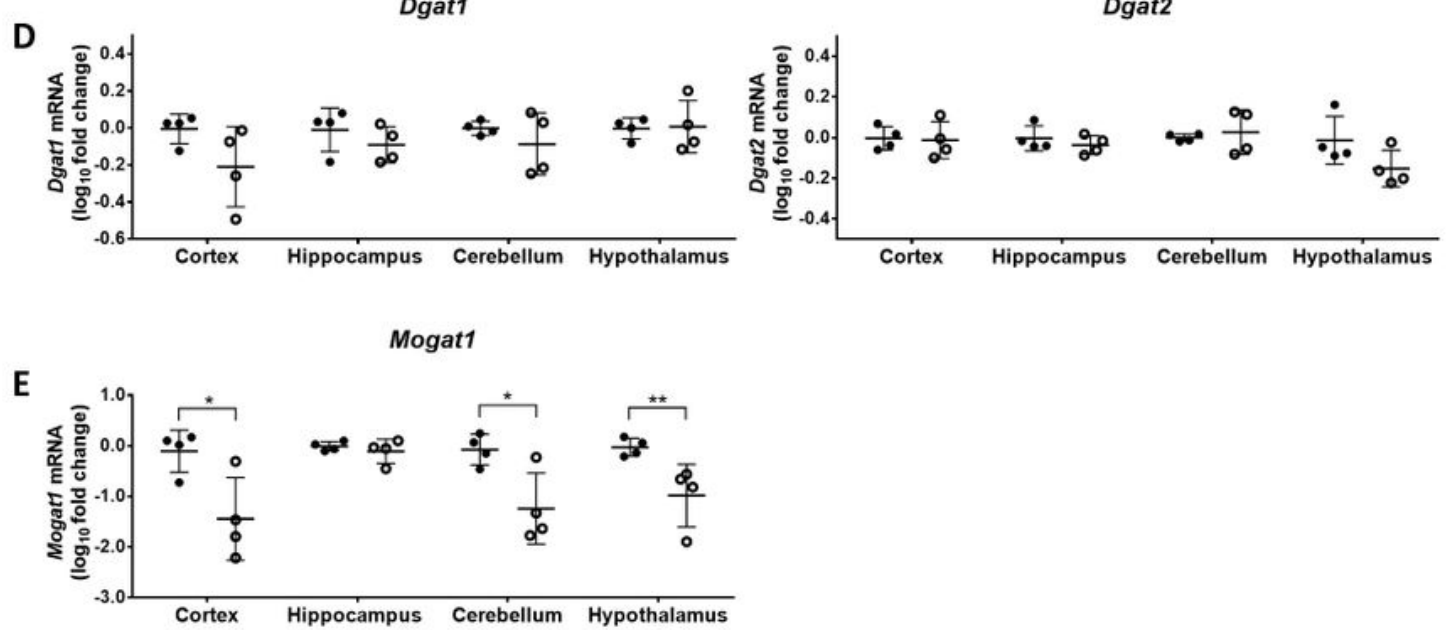

Figure 2 
mRNA expression levels of enzymes involved in glycerolipid synthesis in cerebral cortex, hippocampus, cerebellum and hypothalamus of Agpat2+/+ and Agpat2-/- mice. mRNA expression levels of each gene were normalized by Cyclophilin mRNA expression levels and expressed as fold-change compared to wild type (Agpat2+/+) mice, by $2-\Delta \Delta C T$ method. * $p<0.05$, ** $p<0.01$, *** $p<0.001$ and $* * \star * ~ p<0.0001$. Mean values were analyzed by unpaired Student's t test. $n=4$ animals per group (two male and two female per group; except for genes measured in the hypothalamus of wild type mice, in which there are 3 males and 1 female per group). N.D.: not detected.

\section{A}

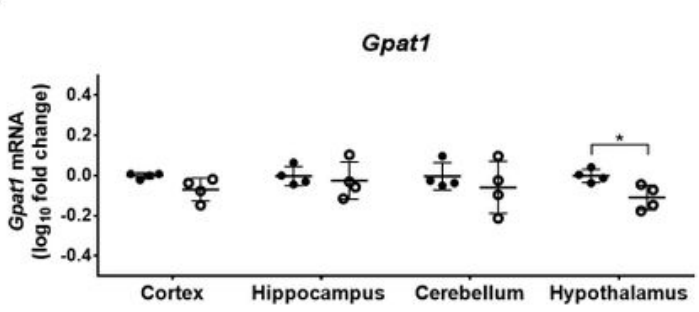

B

Agpat1

- Agpat2 $2^{+/+}$

- Agpat2 ${ }^{\%}$
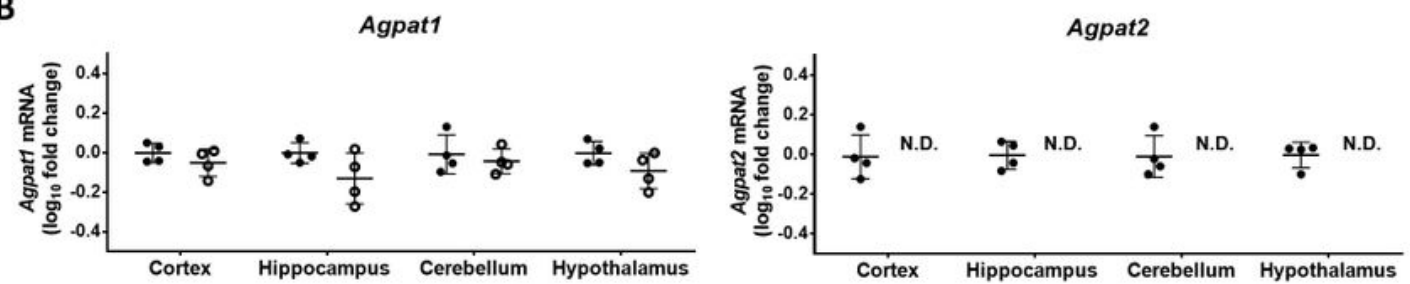

Agpat3

Agpat4
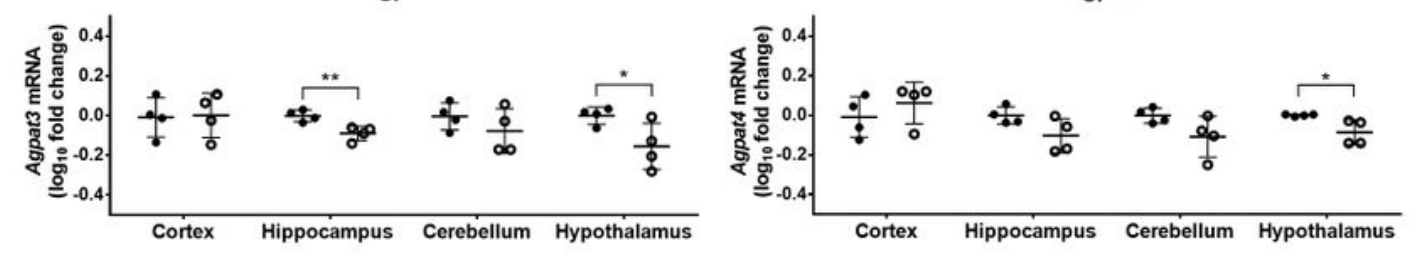

C
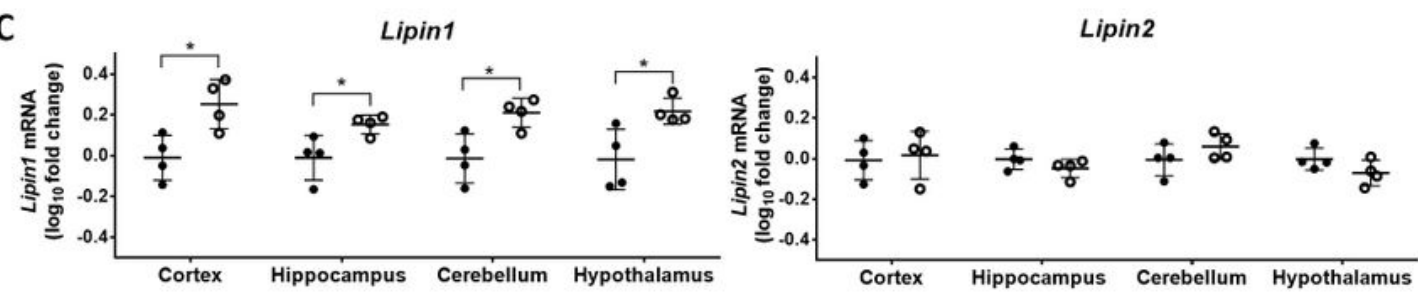

Dgat1

Dgat2
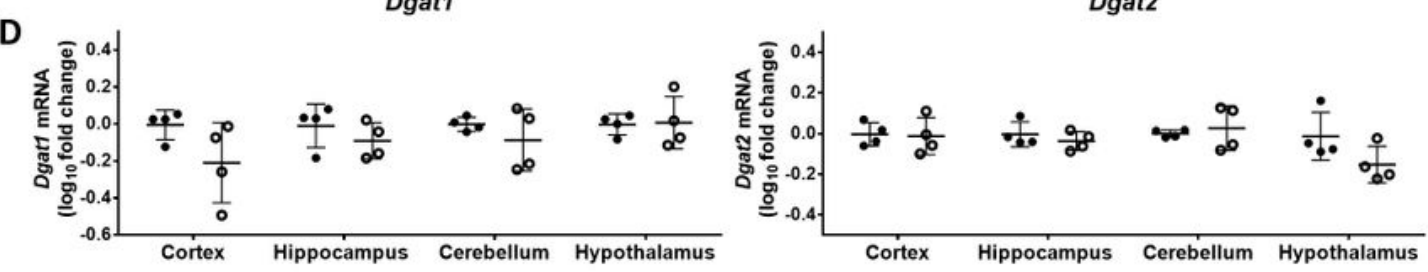

Mogat1

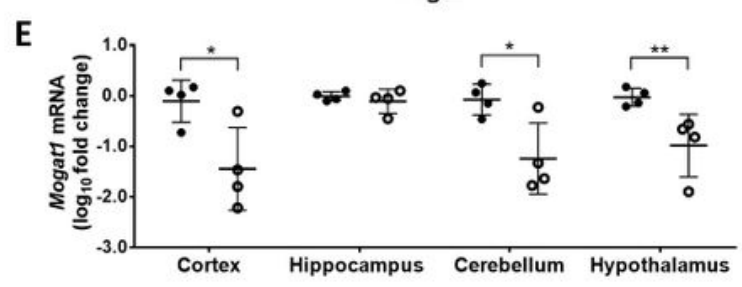




\section{Figure 2}

mRNA expression levels of enzymes involved in glycerolipid synthesis in cerebral cortex, hippocampus, cerebellum and hypothalamus of Agpat2+/+ and Agpat2-/- mice. mRNA expression levels of each gene were normalized by Cyclophilin mRNA expression levels and expressed as fold-change compared to wild type (Agpat2+/+) mice, by 2- $\Delta \Delta C$ CT method. * $p<0.05$, $* \star p<0.01$, ${ }^{\star \star *} p<0.001$ and ${ }^{* \star \star *} p<0.0001$. Mean values were analyzed by unpaired Student's $t$ test. $n=4$ animals per group (two male and two female per group; except for genes measured in the hypothalamus of wild type mice, in which there are 3 males and 1 female per group). N.D.: not detected. 
A

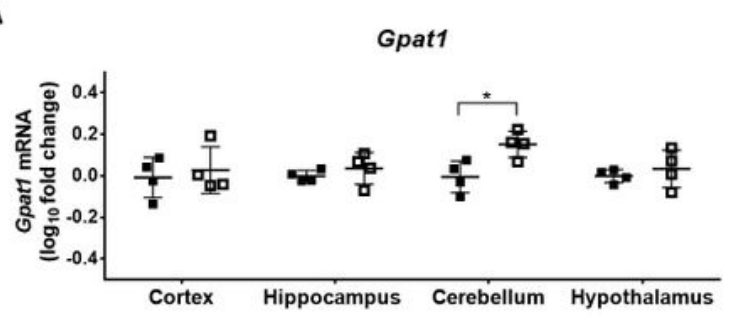

B
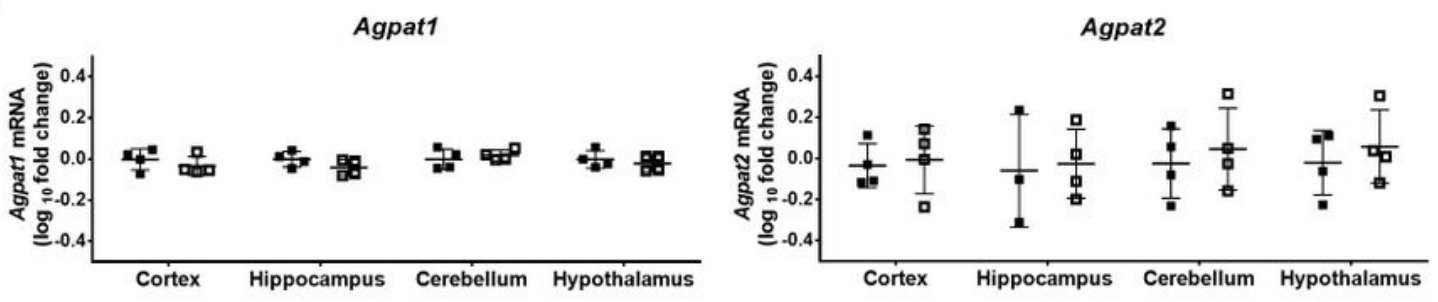

Agpat3

- Lepr ${ }^{+/+}$

- Lepr dbadb
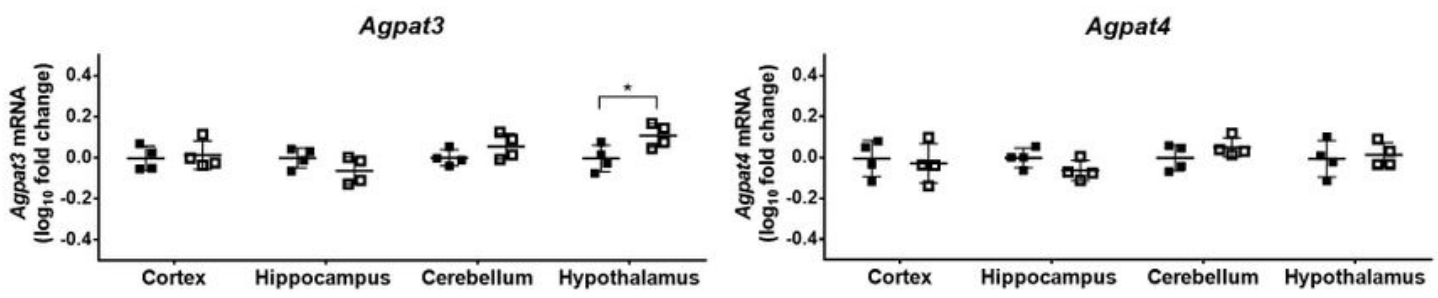

C
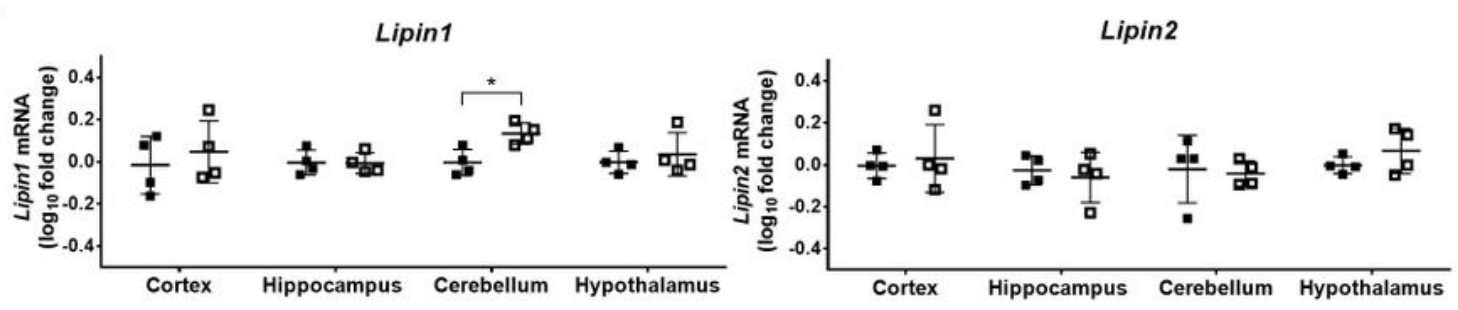

D

$$
\text { Dgat1 }
$$

Dgat2
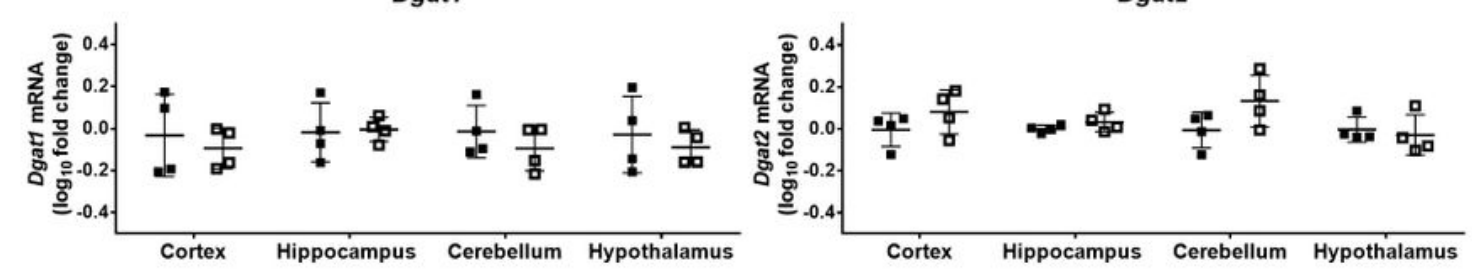

E

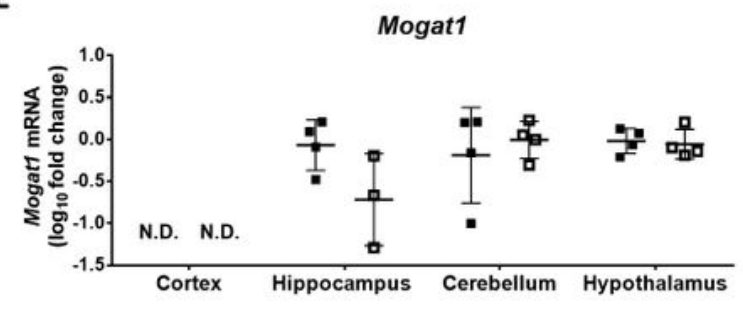

Figure 3

mRNA expression levels of enzymes involved in glycerolipid synthesis in cerebral cortex, hippocampus, cerebellum and hypothalamus of Lepr+/+ and Leprdb/db mice. mRNA expression levels of each gene were normalized by Cyclophilin mRNA expression levels and expressed as fold-change compared to wild type $($ Lepr $+/+)$ mice, by $2-\Delta \Delta$ CT method. * $p<0.05$, ** $p<0.01$, *** $p<0.001$ and **** $p<0.0001$. Mean 
values were analyzed by unpaired Student's t test. $n=4$ animals per group (two male and two female per group). N.D.: not detected.

A

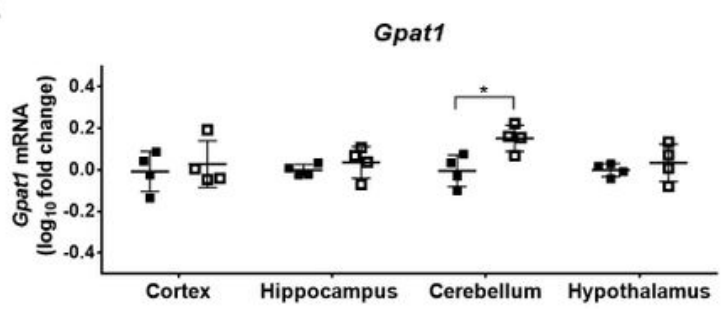

B

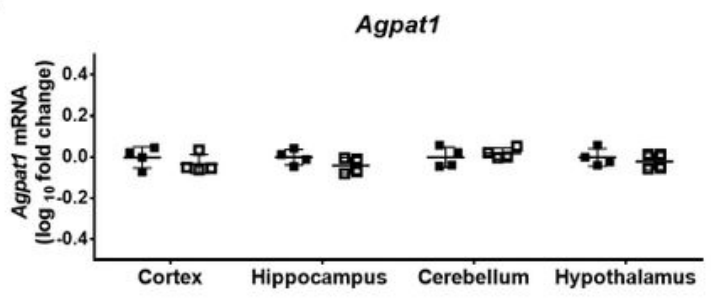

- Lepr $^{+/+}$
- Lepr
db/db

Agpat3
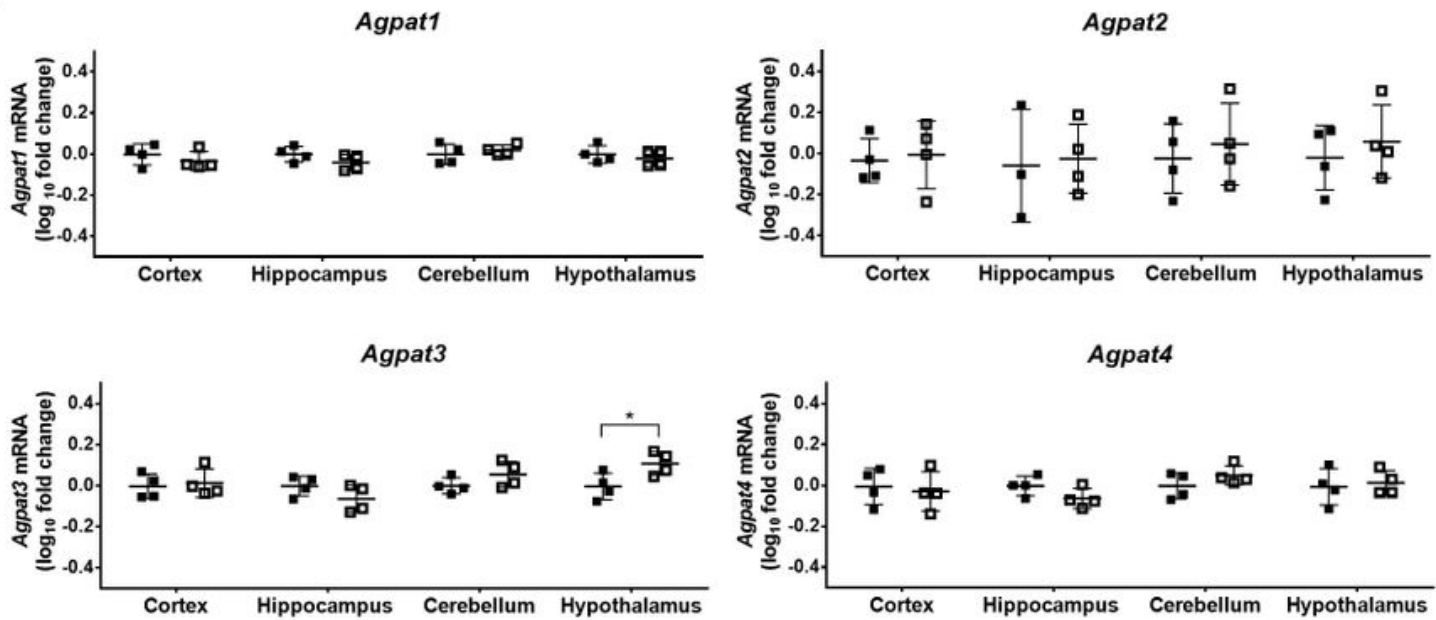

C
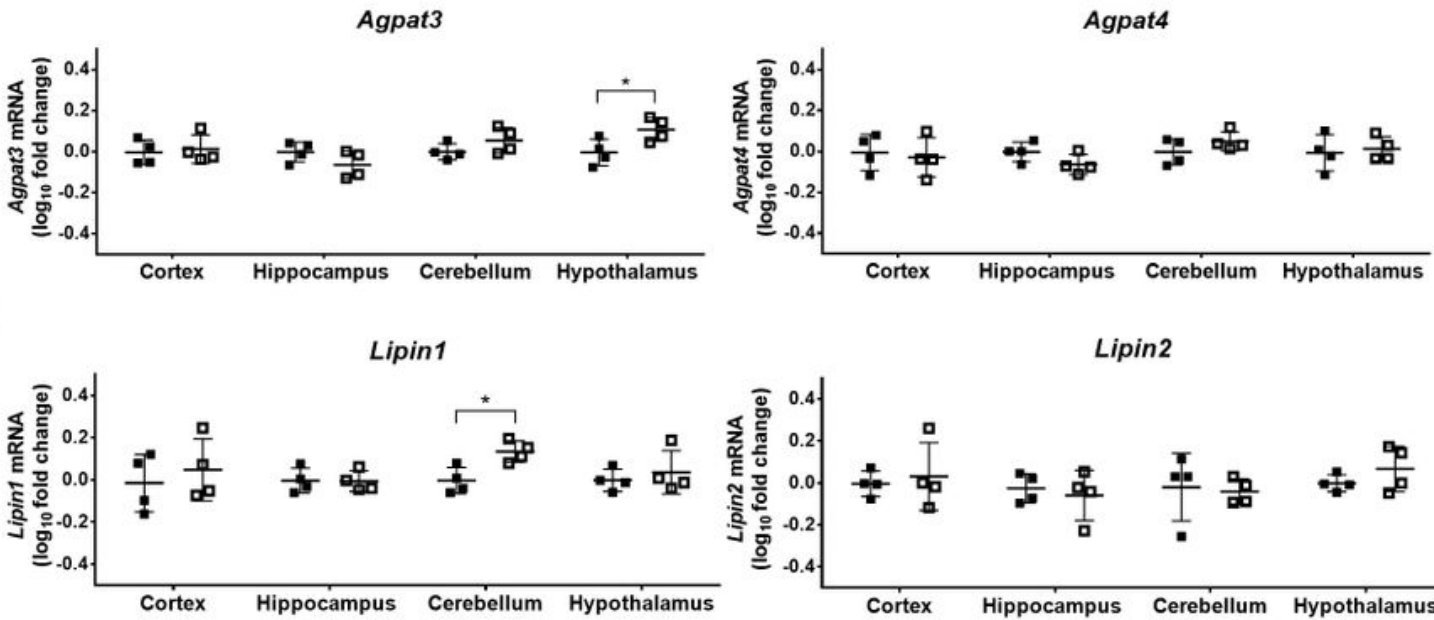

D
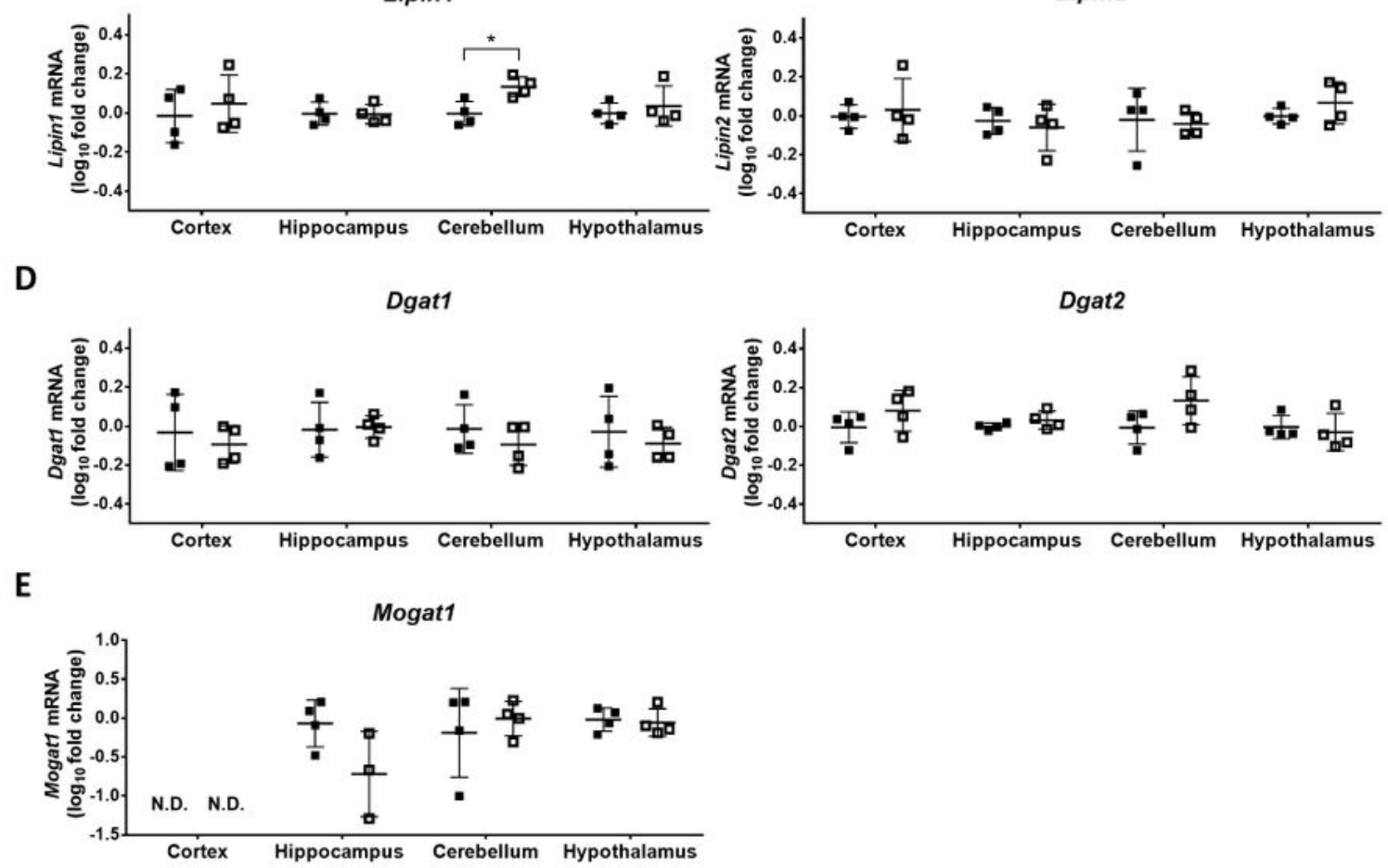

Figure 3

mRNA expression levels of enzymes involved in glycerolipid synthesis in cerebral cortex, hippocampus, cerebellum and hypothalamus of Lepr+/+ and Leprdb/db mice. mRNA expression levels of each gene were normalized by Cyclophilin mRNA expression levels and expressed as fold-change compared to wild 
type $($ Lepr+/+) mice, by $2-\Delta \Delta$ CT method. * $p<0.05$, ** $p<0.01$, *** $p<0.001$ and **** $p<0.0001$. Mean values were analyzed by unpaired Student's t test. $n=4$ animals per group (two male and two female per group). N.D.: not detected.

A

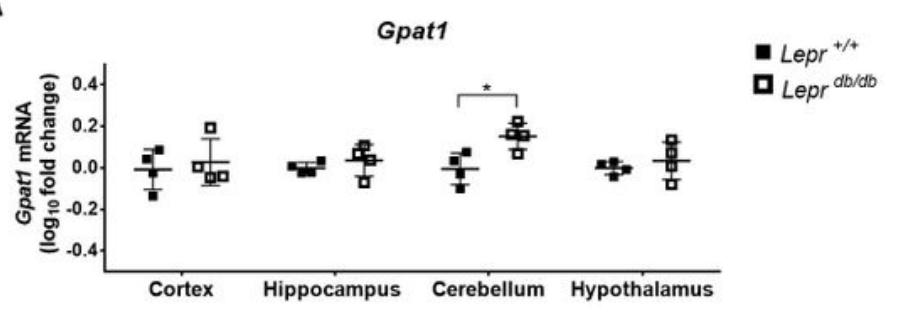

B
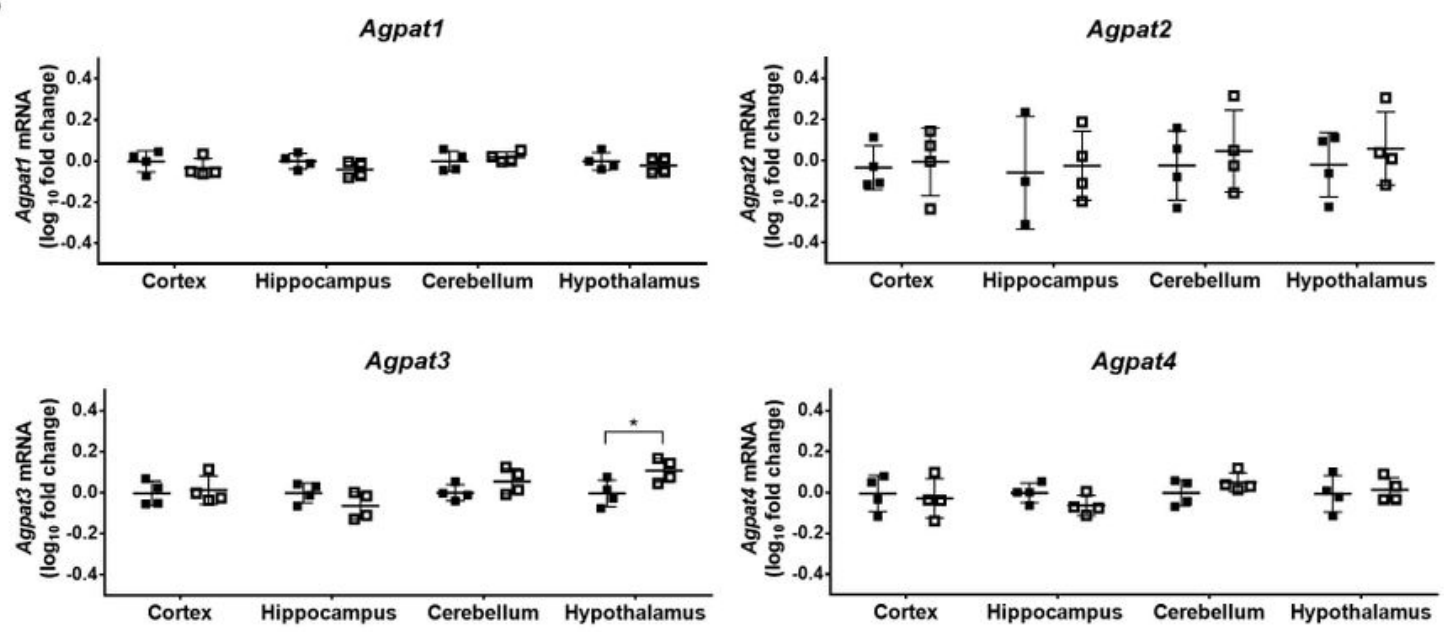

C
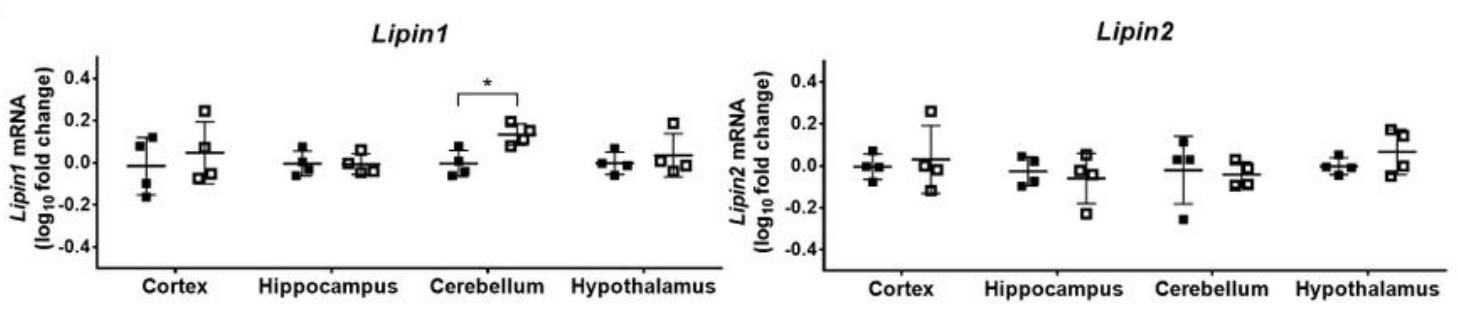

D
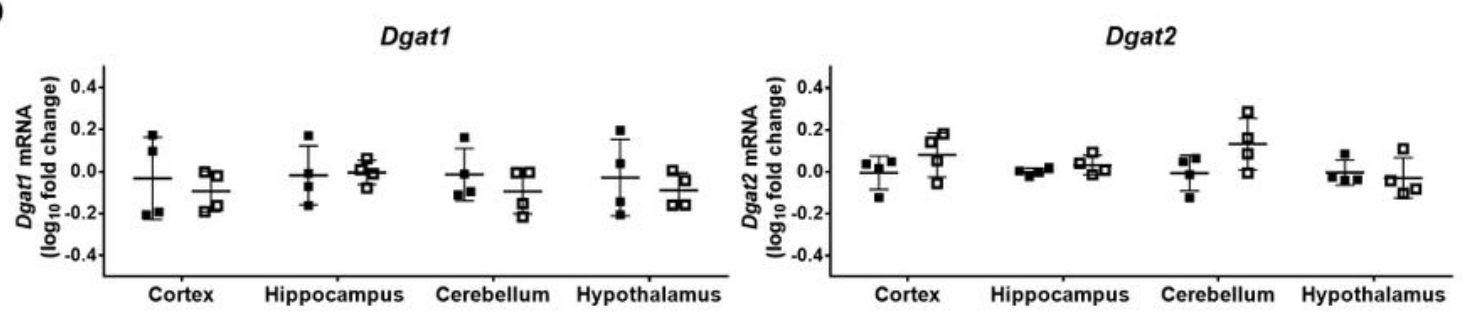

E

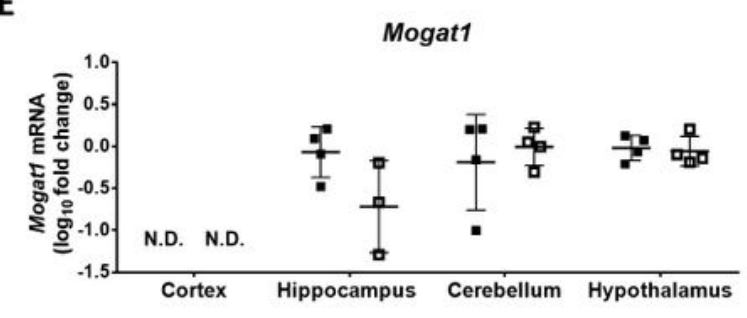

Figure 3

mRNA expression levels of enzymes involved in glycerolipid synthesis in cerebral cortex, hippocampus, cerebellum and hypothalamus of Lepr+/+ and Leprdb/db mice. mRNA expression levels of each gene 
were normalized by Cyclophilin mRNA expression levels and expressed as fold-change compared to wild

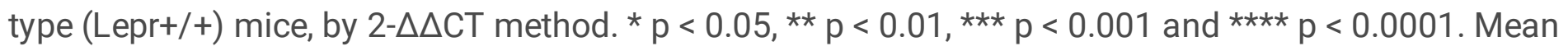
values were analyzed by unpaired Student's $t$ test. $n=4$ animals per group (two male and two female per group). N.D.: not detected.

A

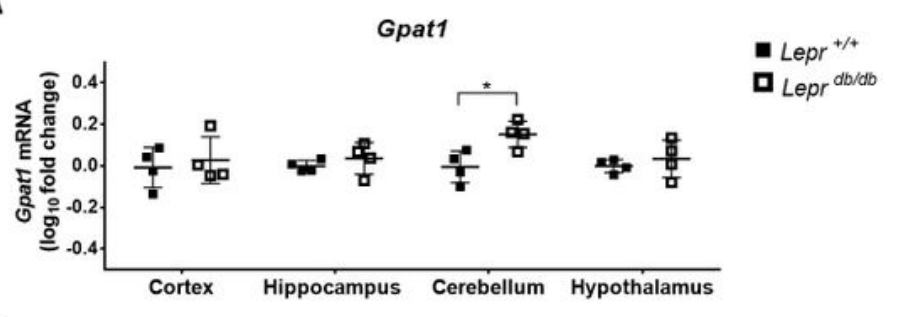

B
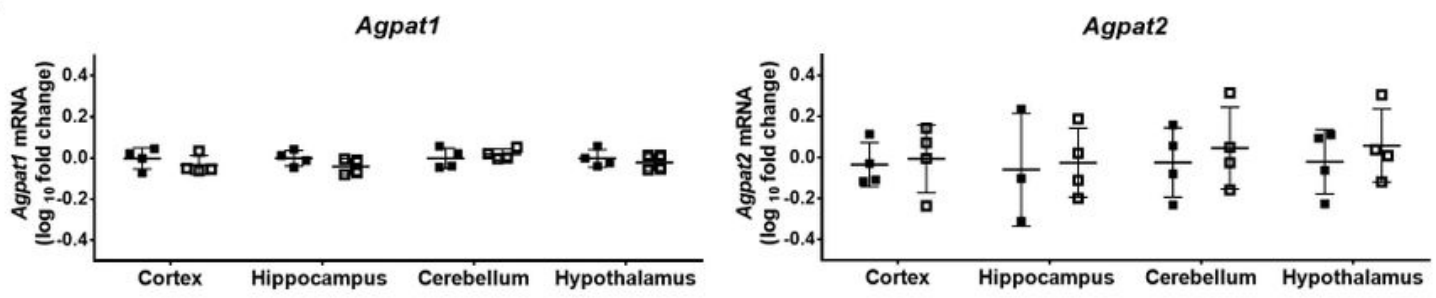

Agpat3
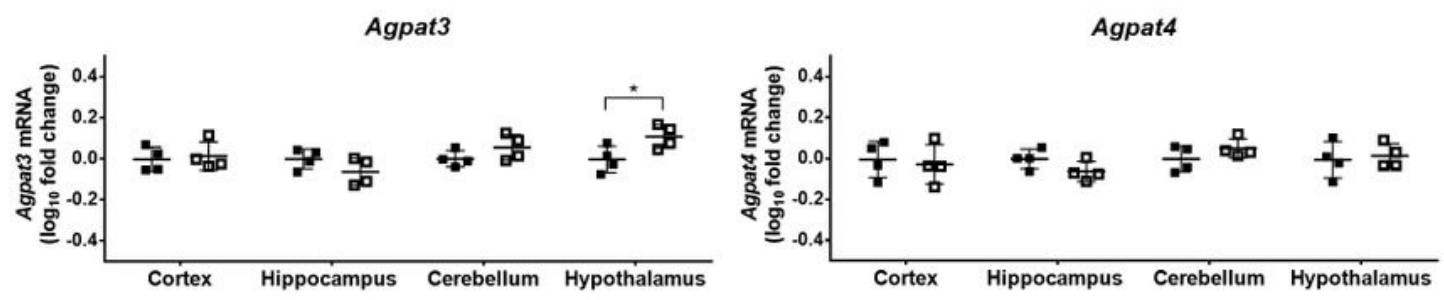

C
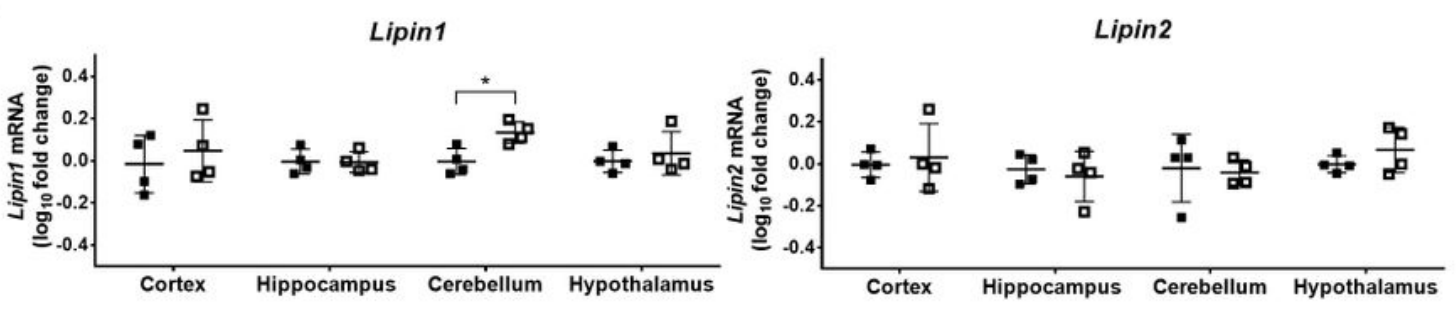

D
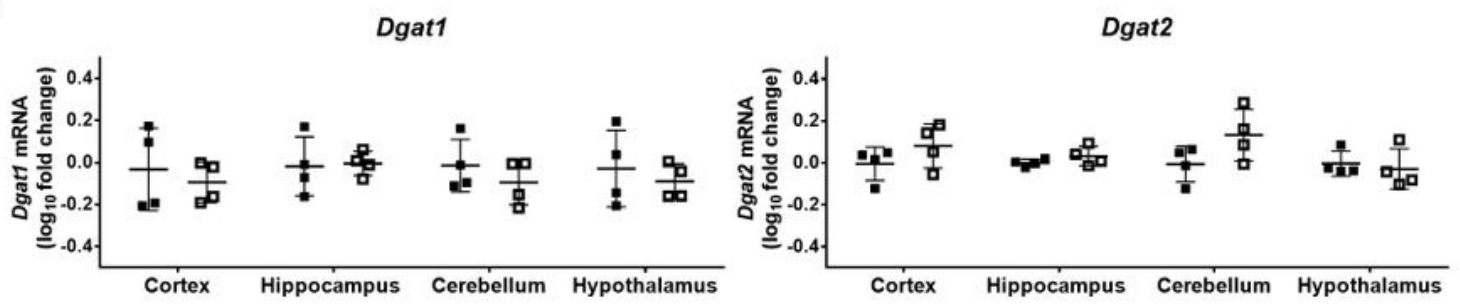

E

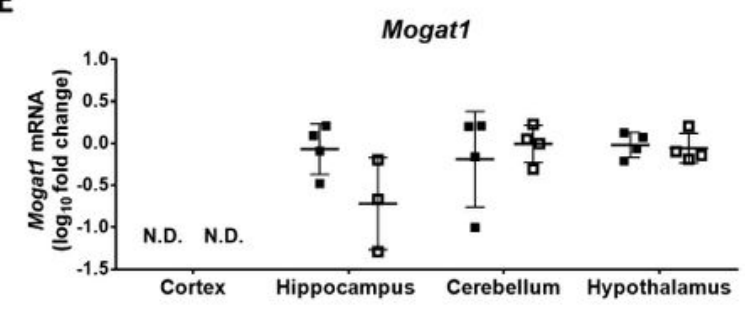

Figure 3 
mRNA expression levels of enzymes involved in glycerolipid synthesis in cerebral cortex, hippocampus, cerebellum and hypothalamus of Lepr+/+ and Leprdb/db mice. mRNA expression levels of each gene were normalized by Cyclophilin mRNA expression levels and expressed as fold-change compared to wild type (Lepr $+/+)$ mice, by $2-\Delta \Delta$ CT method. ${ }^{*} p<0.05$, $* * p<0.01$, $* \star * p<0.001$ and ${ }^{* \star * *} p<0.0001$. Mean values were analyzed by unpaired Student's $t$ test. $n=4$ animals per group (two male and two female per group). N.D.: not detected.

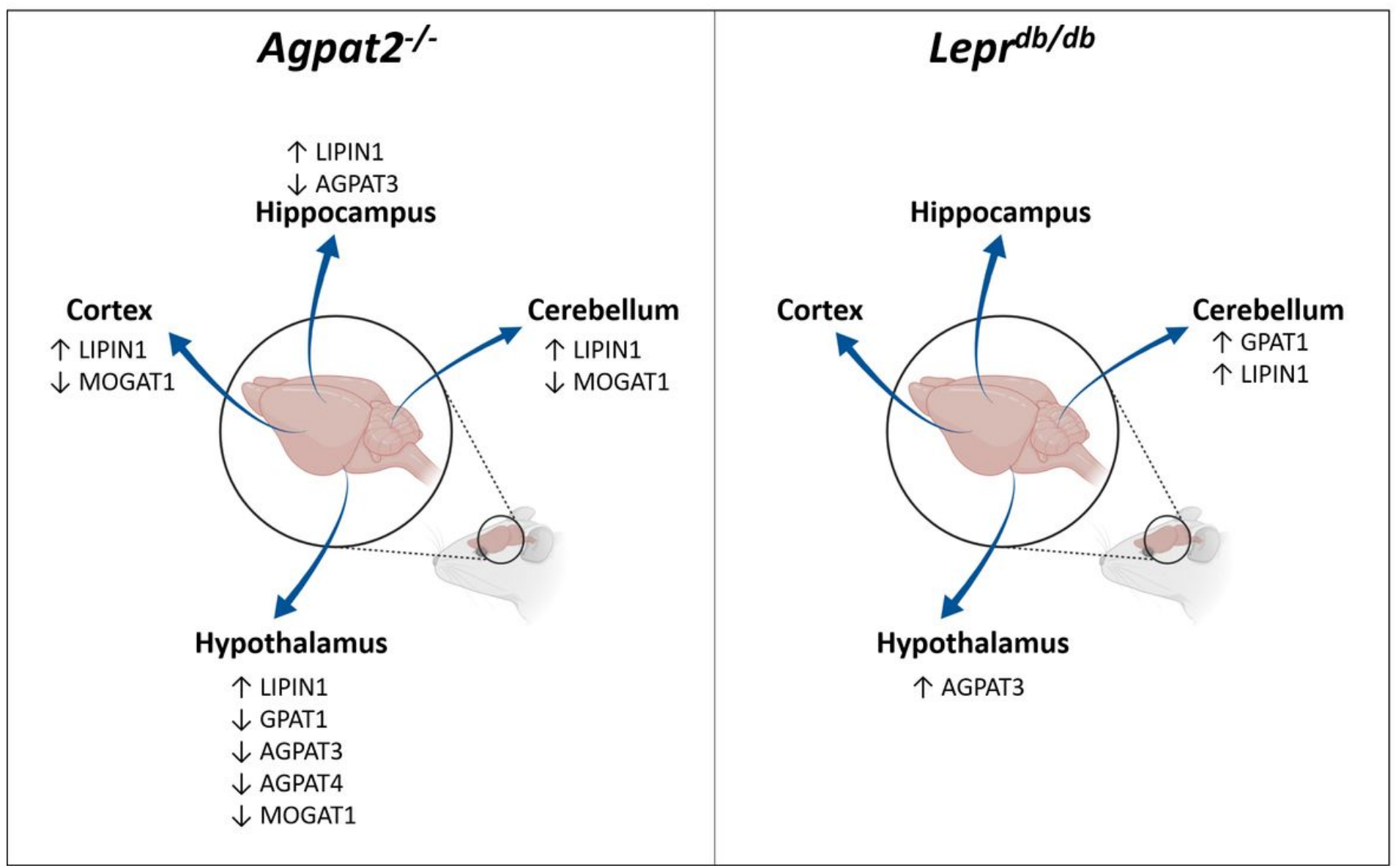

\section{Figure 4}

Summary of the significant changes in mRNA levels of the enzymes involved in glycerolipids synthesis in Agpat2-/- and Leprdb/db mice. The figure shows the genes that presented statistically significant changes in mRNA expression in comparison to wild type mice. $\uparrow$ indicates an increase in the mRNA expression levels with respect to wild type littermates. $\downarrow$ indicates a decrease in the mRNA expression levels with respect to wild type littermates. 


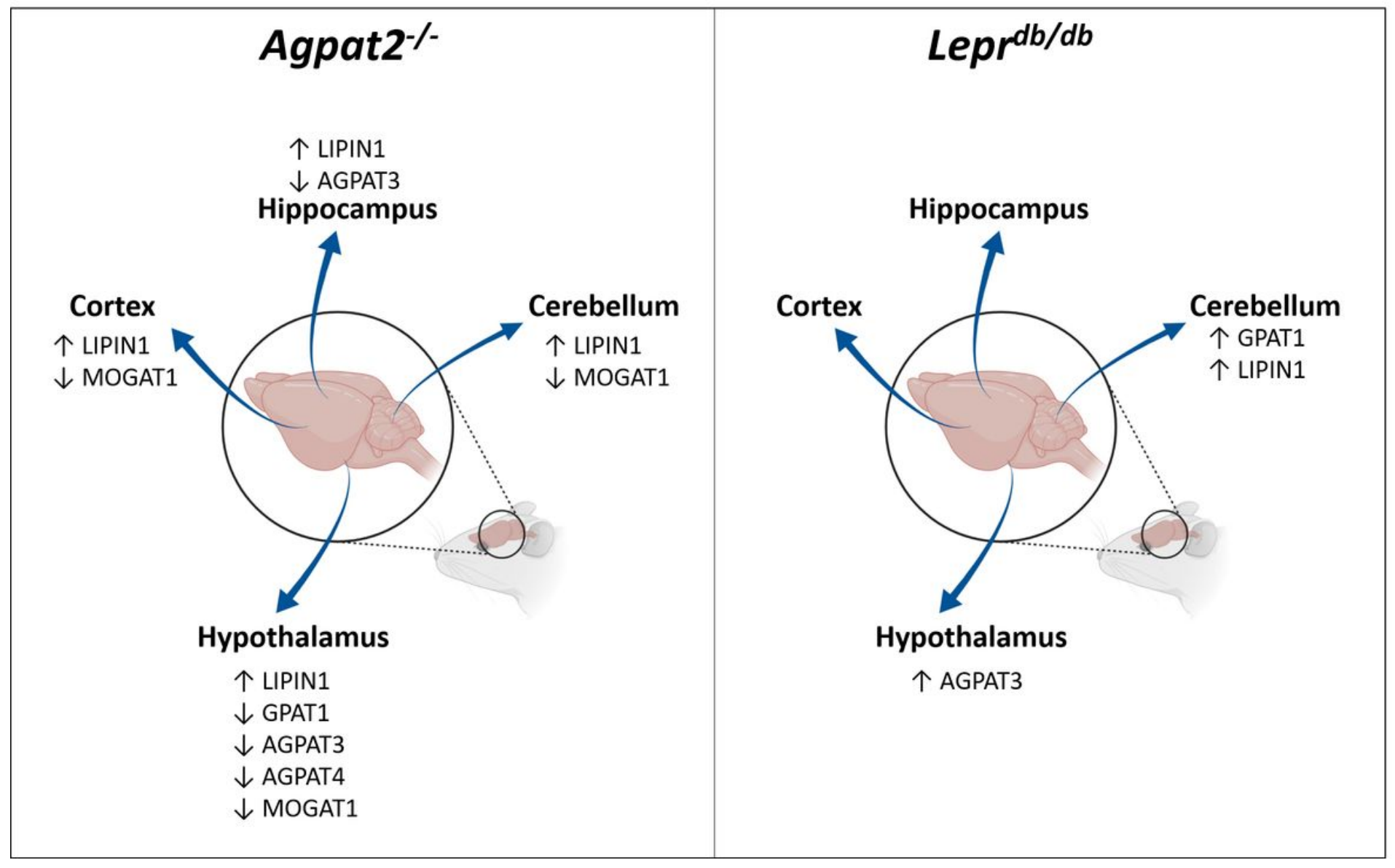

\section{Figure 4}

Summary of the significant changes in mRNA levels of the enzymes involved in glycerolipids synthesis in Agpat2-/- and Leprdb/db mice. The figure shows the genes that presented statistically significant changes in mRNA expression in comparison to wild type mice. $\uparrow$ indicates an increase in the mRNA expression levels with respect to wild type littermates. $\downarrow$ indicates a decrease in the mRNA expression levels with respect to wild type littermates. 


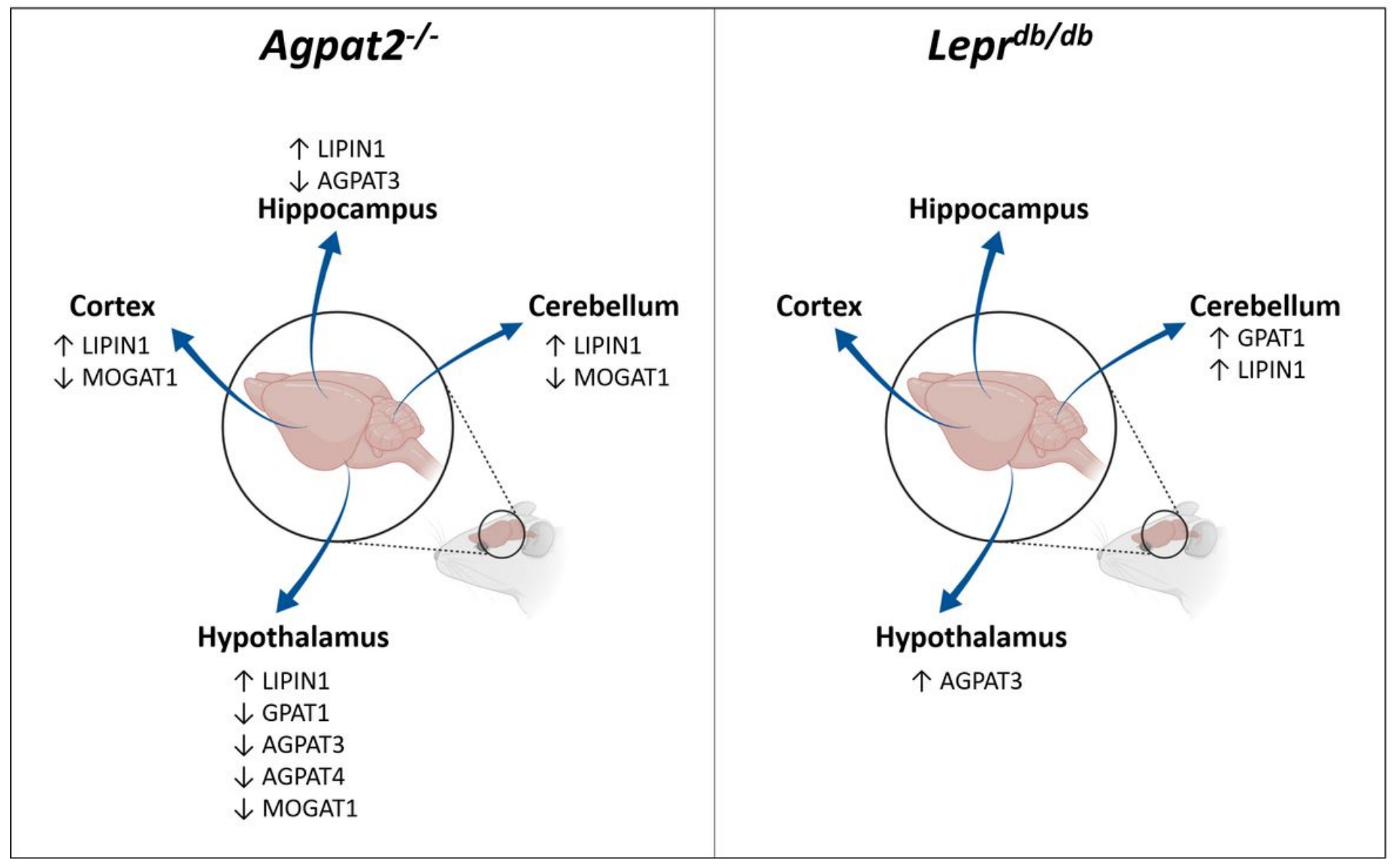

\section{Figure 4}

Summary of the significant changes in mRNA levels of the enzymes involved in glycerolipids synthesis in Agpat2-/- and Leprdb/db mice. The figure shows the genes that presented statistically significant changes in mRNA expression in comparison to wild type mice. $\uparrow$ indicates an increase in the mRNA expression levels with respect to wild type littermates. $\downarrow$ indicates a decrease in the mRNA expression levels with respect to wild type littermates. 


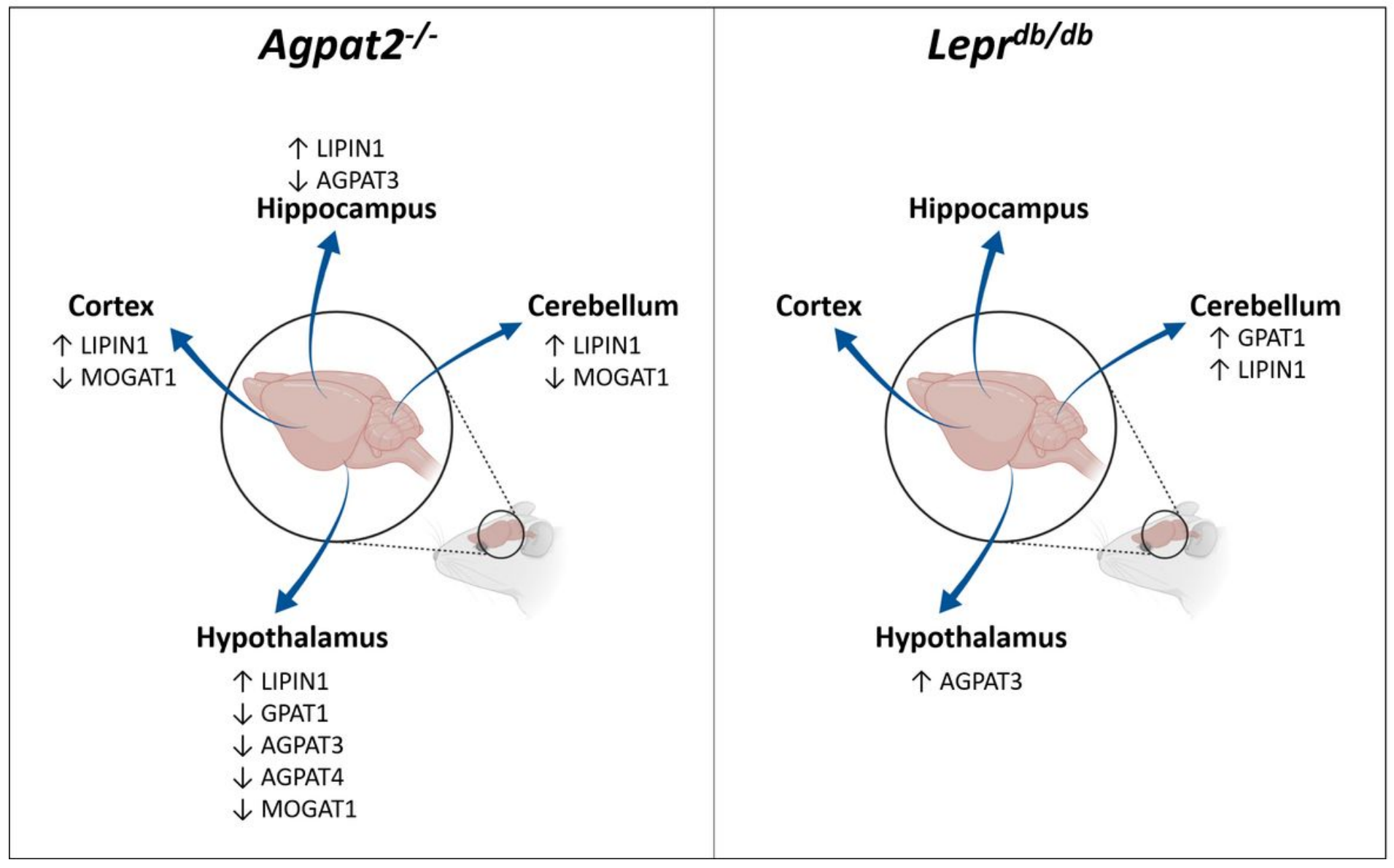

Figure 4

Summary of the significant changes in mRNA levels of the enzymes involved in glycerolipids synthesis in Agpat2-/- and Leprdb/db mice. The figure shows the genes that presented statistically significant changes in mRNA expression in comparison to wild type mice. $\uparrow$ indicates an increase in the mRNA expression levels with respect to wild type littermates. $\downarrow$ indicates a decrease in the mRNA expression levels with respect to wild type littermates.

\section{Supplementary Files}

This is a list of supplementary files associated with this preprint. Click to download.

- SupplementaryDataGonzalezHodaretalAFTER2NDREVISION.docx

- SupplementaryDataGonzalezHodaretalAFTER2NDREVISION.docx

- SupplementaryDataGonzalezHodaretalAFTER2NDREVISION.docx

- SupplementaryDataGonzalezHodaretalAFTER2NDREVISION.docx

- Tablessupplementarydata.xlsx

- Tablessupplementarydata.xlsx

- Tablessupplementarydata.xlsx 
- Tablessupplementarydata.xIsx

Page 34/34 